\title{
Neural correlates of goal-directed enhancement and suppression of visual stimuli in the absence of conscious perception
}

\author{
Susan L. Travis ${ }^{1}$ • Paul E. Dux ${ }^{2}$ - Jason B. Mattingley ${ }^{1,2}$ \\ Published online: 30 October 2018 \\ (C) The Psychonomic Society, Inc. 2019
}

\begin{abstract}
An observer's current goals can influence the processing of visual stimuli. Such influences can work to enhance goal-relevant stimuli and suppress goal-irrelevant stimuli. Here, we combined behavioral testing and electroencephalography (EEG) to examine whether such enhancement and suppression effects arise even when the stimuli are masked from awareness. We used a feature-based spatial cueing paradigm, in which participants searched four-item arrays for a target in a specific color. Immediately before the target array, a nonpredictive cue display was presented in which a cue matched or mismatched the searched-for target color, and appeared either at the target location (spatially valid) or another location (spatially invalid). Cue displays were masked using continuous flash suppression. The EEG data revealed that target-colored cues produced robust $\mathrm{N} 2 \mathrm{pc}$ and $\mathrm{N}_{\mathrm{T}}$ responses — both signatures of spatial orienting - and distractor-colored cues produced a robust $\mathrm{P}_{\mathrm{D}}$ - a signature of suppression. Critically, the cueing effects occurred for both conscious and unconscious cues. The $\mathrm{N} 2 \mathrm{pc}$ and $\mathrm{N}_{\mathrm{T}}$ were larger in the aware versus unaware cue condition, but the $\mathrm{P}_{\mathrm{D}}$ was roughly equivalent in magnitude across the two conditions. Our findings suggest that top-down control settings for task-relevant features elicit selective enhancement and suppression even in the absence of conscious perception. We conclude that conscious perception modulates selective enhancement of visual features, but suppression of those features is largely independent of awareness.
\end{abstract}

Keywords Attentional capture - Visual awareness · Attention: Selective

The relationship between attention and perceptual awareness has been the subject of a lengthy and intense debate (Chica \& Bartolomeo, 2012; Chun \& Wolfe, 2000; Cohen, Cavanagh, Chun, \& Nakayama, 2012; De Brigard \& Prinz, 2010; Dehaene, Changeux, Naccache, Sackur, \& Sergent, 2006; Iwasaki, 1993; Koch \& Tsuchiya, 2007, 2012; Lamme, 2003, 2006; Mole, 2008; Posner, 1994; Prinz, 2011; Tallon-Baudry,

The original version of this article was revised: This article was originally published electronically on the publisher's internet portal (currently SpringerLink) on 30 October 2018 with open access. With the author(s)' decision to step back from Open Choice, the copyright of the article changed on 30 December to $\odot$ The Psychonomic Society, Inc. and the article is forthwith distributed under the terms of copyright.

Electronic supplementary material The online version of this article (https://doi.org/10.3758/s13414-018-1615-7) contains supplementary material, which is available to authorized users.

Susan L. Travis

s.travis@uq.edu.au

1 Queensland Brain Institute, The University of Queensland, St Lucia, Queensland 4072, Australia

2 School of Psychology, The University of Queensland, St Lucia 4072, Australia
Campana, Park, \& Babo-Rebelo, 2018; van Boxtel, 2017; van Boxtel, Tsuchiya, \& Koch, 2010; Wyart \& Tallon-Baudry, 2008). Many theorists have suggested that the two processes are inseparable, if not identical (Chun \& Wolfe, 2000; Cohen et al., 2012; De Brigard \& Prinz, 2010; Mack \& Rock, 1998; Merikle \& Joordens, 1997; Mole, 2008; O`Regan \& Noe, 2001; Posner, 1994; Prinz, 2011; Velmans, 1996), whereas others have argued that attention and awareness are supported by distinct neural processes, and are readily dissociated from one another (Baars, 1997, 2005; Bachmann, 2006; Block, 2005; Dehaene et al., 2006; Iwasaki, 1993; Kentridge, Heywood, \& Weiskrantz, 1999a; Kentridge, Heywood, \& Weiskrantz, 2004; Koch, 2004; Lamme, 2003; Maier et al., 2008; Naccache, Blandin, \& Dehaene, 2002; Koch \& Tsuchiya, 2007; van Boxtel et al., 2010; Watanabe et al., 2011; Woodman \& Luck, 2003a).

A central dilemma in the debate is that, under normal circumstances, attended stimuli tend to be consciously perceived; likewise, salient stimuli that occupy conscious perception frequently become the focus of attention. Koch and Tsuchiya (2007) have proposed that the optimal approach for investigating associations and dissociations between attention and awareness is to use a two-by-two crossed experimental design. Under this framework, participants are instructed either to attend to or ignore sensory stimuli, and these events 
are presented so that they are either consciously perceived or manipulated (via masking, etc.) so that they cannot be consciously reported. Here, we addressed the question of the relationship between spatial attention and perceptual awareness using a recently developed feature-based cueing paradigm (Lamy, Alon, Carmel, \& Shalev, 2015) in which cue events were masked so that they were not available for conscious report on roughly half the trials. We combined reaction time (RT) measures of performance with electroencephalography (EEG) to examine the independent effects of attention and awareness on feature-based cueing effects (e.g., Folk \& Remington, 1999; Folk, Remington, \& Johnston, 1992; Folk, Remington, \& Wright, 1994; Gibson \& Amelio, 2000; Gibson \& Kelsey, 1998; Yantis \& Egeth, 1999).

As is typical in feature-based cueing experiments (e.g., Folk \& Remington, 1999; Folk et al., 1992; Folk et al., 1994; Gibson \& Amelio, 2000; Gibson \& Kelsey, 1998; Yantis \& Egeth, 1999), targets presented at the same location as a targetcolored cue (valid trials) produce faster RTs than targets presented at a different location (invalid trials). Interestingly, this feature-based cueing effect seems to occur even when cues are not consciously perceived due to masking (e.g., Ansorge \& Neumann, 2005; Hsieh, Colas, \& Kanwisher, 2011; Ivanoff \& Klein, 2003; Lamy et al., 2015). In most previous studies, the feature-based cueing effect has been quantified by comparing differences in reaction times (RTs) between valid and invalid cue conditions (e.g., Folk \& Remington, 1999; Folk et al., 1992; Folk et al., 1994; Gibson \& Amelio, 2000; Gibson \& Kelsey, 1998; Yantis \& Egeth, 1999). However, RT measures index the end result of an accumulated sequence of processing stages between stimulus onset and motor response (Sternberg, 1969). It is thus desirable to incorporate a more continuous measure of attentional allocation to examine the time course of feature-based cueing effects in such experiments. To this end, several investigators have employed event-related potentials (ERPs), such as the $\mathrm{N} 2$ posterior contralateral $(\mathrm{N} 2 \mathrm{pc})$ component, to measure the neural dynamics of feature-based spatial cueing effects (Eimer, 1996; Eimer \& Kiss, 2008; Heinze, Luck, Mangun, \& Hillyard, 1990; Kiss, van Velzen, \& Eimer, 2008; Luck, 2005; Luck \& Hillyard, 1994; Woodman \& Luck, 1999, 2003b).

Several feature-based cueing studies have found evidence for an N2pc response to target-relevant cues that were masked from awareness (e.g., Ansorge, Horstmann, \& Worschech, 2010; Ansorge, Kiss, \& Eimer, 2009; Woodman \& Luck, 2003a). There are, however, some important limitations with the designs used in these studies that limit the extent to which clear conclusions can be drawn regarding the relationship between spatial attention and perceptual awareness. Ansorge et al. (2010) and Ansorge et al. (2009) found that masked cues captured attention when they were task relevant, but not when they were task irrelevant, suggesting that feature-based cueing effects can be elicited even when cues are not consciously perceived. In these studies, however, spatial orienting was not measured under both aware and unaware conditions, so the independent effects of selective attention and awareness could not be assessed.

Woodman and Luck (2003a) presented search displays that contained targets and distractors that were masked using object substitution masking (OSM). They measured N2pc responses to the targets and distractors under delayed offset and cotermination masking conditions. Interestingly, the authors found an N2pc response for both delayed offset and cotermination trials, and this response did not differ in magnitude between the masking conditions, suggesting that feature-based cueing effects might be independent of awareness. Critically, however, their participants' performance on the search task was significantly above chance even in the critical delayed-mask offset condition, suggesting that their participants might have been aware of the target and distractor stimuli in the "unaware" condition.

Lamy et al. (2015) addressed some of the issues with these previous studies by using continuous flash suppression (CFS; Tsuchiya \& Koch, 2005; Tsuchiya, Koch, Gilroy, \& Blake, 2006) to mask brief visual cues presented to one eye in a feature-based cueing task. In their task, a cue display containing a single colored stimulus, which either matched the target color or was a distractor color, was presented to one eye. This cue display was masked by presenting a high-contrast flickering stimulus in the other eye. Importantly, stimulus parameters were held constant for every trial throughout the experiment, and participants were asked to report their awareness of the cue on each trial. After the cue display, targets appeared at valid or invalid locations. Participants searched for a color-defined target and reported its orientation, before indicating their awareness of the preceding cue. Valid target-colored cues produced faster RTs to targets than invalid target-colored cues, as expected. Critically, however, Lamy et al. (2015) found that the validity effect was similar in magnitude for consciously perceived and unperceived cues, suggesting that the feature-based cueing effect arises even in the absence of conscious perception of the triggering cues. The authors also found that spatially valid distractor-colored cues increased RTs to the target compared with invalid distractor-colored cues, resulting in a same location cost (see also Anderson \& Folk, 2012; Belopolsky, Schreij, \& Theeuwes, 2010; Carmel \& Lamy, 2014; Lamy et al., 2015; Eimer, Kiss, Press, \& Sauter, 2009; Folk \& Remington, 2008; Lamy \& Egeth, 2003; Lamy, Leber, \& Egeth, 2004; Schoeberl, Ditye, \& Ansorge, 2018; Schönhammer \& Kerzel, 2013). Interestingly, the same location cost was found for aware trials but not for unaware trials, suggesting that the same-location cost depends on awareness of relevant cue stimuli.

Here, we sought to replicate and extend the pioneering work of Lamy et al. (2015) using a feature-based cueing task combined with CFS to manipulate participants' awareness of visual cues. We combined behavioral testing and 
electroencephalography (EEG) to ask whether goal-relevant stimuli in a feature-based spatial attention task produce cueing effects even when the "cueing" events are not consciously perceived. In Experiment 1 we ran a direct replication of the behavioral task developed by Lamy et al. (2015), as described in detail above, but using a larger sample of participants and more experimental trials per condition. In Experiment 2, we recorded EEG while participants performed the same behavioral task as in Experiment 1, with the aim of investigating whether the neural signatures of feature-based cueing effects are similar for aware and unaware cues. Finally, in Experiment 3 , we modified the spatial cueing task to determine whether the observed effects of aware and unaware cues on RTs and ERPs reflected selective enhancement of task-relevant features and/or active suppression of task-irrelevant features.

\section{Experiment 1}

Experiment 1 was a direct replication of Experiment 1 from Lamy et al. (2015). Cues could appear at the same location as the target or at a different location, and they either matched the target color or were a different color. Cues were masked using CFS, such that participants were only aware of the cues on approximately half of the trials. Participants were asked to identify the target's orientation as quickly as possible and, following this, report their awareness of the cue. In line with the findings of Lamy et al. (2015), we predicted that valid target-colored cues would elicit faster responses to targets than would invalid target-colored cues, and the magnitude of this same location benefit would not differ between aware and unaware trials. We also hypothesized that valid distractorcolored cues would elicit slower responses to targets than would invalid distractor-colored cues, but only when the cues were consciously perceived, in line with the findings of Lamy et al. (2015).

\section{Method}

\section{Participants}

Twenty-seven individuals participated in Experiment 1 (16 females, mean age $=22.74$ years, $S D=3.50$ ). To increase statistical power and, therefore, the probability of finding potentially small effects, we increased sample size considerably compared with the original study by Lamy et al. $(2015 ; 14$ participants). All participants reported normal or corrected-tonormal vision, and all were naïve to the experimental hypotheses. Each provided informed written consent. The University of Queensland Human Research Ethics Committee approved the studies.

\section{Apparatus, stimuli, and procedure}

Participants were tested in a dimly illuminated room. Stimuli were presented on a 24-inch LCD monitor with a resolution of $1920 \times 1200$ and a refresh rate of $60 \mathrm{~Hz}$. Stimulus delivery and response recording were controlled using a Dell PC running Cogent software (Cogent 2000 Toolbox: Functional Imaging Laboratory, Institute of Cognitive Neuroscience, and Wellcome Department of Imaging Neuroscience) using MATLAB operating under Windows XP. Participants viewed a dichoptic display through a mirror stereoscope, at a viewing distance of approximately $57 \mathrm{~cm}$. To promote stable binocular fusion, the mirrors were adjusted for each individual observer at the beginning of the experimental session.

Participants performed a spatial cueing task, in which they were asked to identify the orientation of a target-colored $\mathrm{T}$ shape (rotated counterclockwise ("left") or clockwise ("right") by $90^{\circ}$; see Fig. 1). Before the target display, a cue display was presented, but masked using continuous flash suppression (CFS), such that participants were aware of the

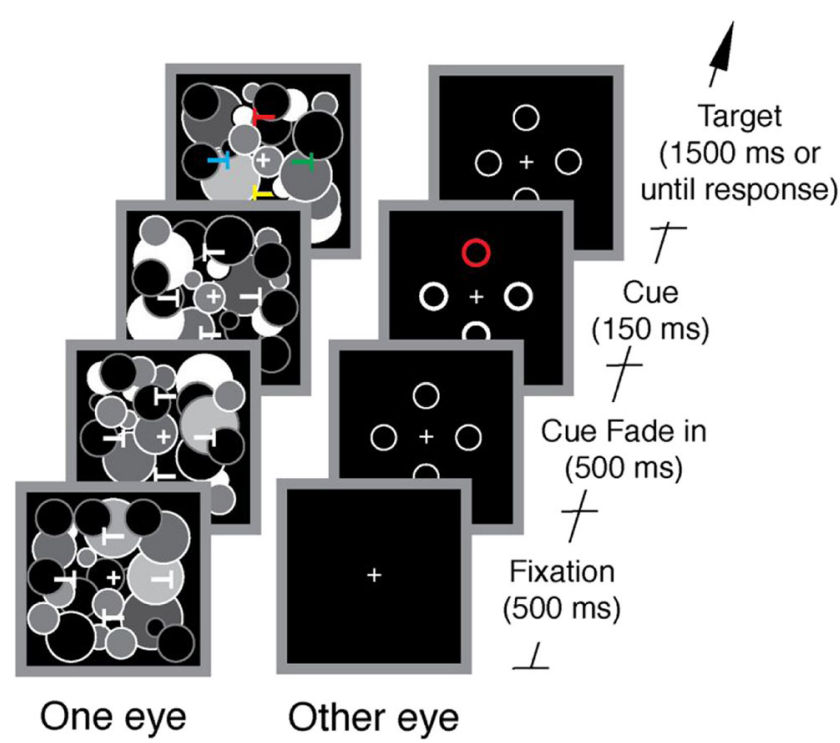

Fig. 1 Schematic of individual trial events in Experiment 1. Participants' task was to report the orientation of the target $\mathrm{T}$ shape and then to indicate whether they were aware of a colored cue stimulus. A flickering mask display ( 20 or $22 \mathrm{~Hz}$ ) and four white T shapes (two rotated 90 degrees clockwise and two rotated 90 degrees counterclockwise) were presented to one eye throughout the experiment. Each trial began with a $500 \mathrm{~ms}$ fixation cross, followed by a $500 \mathrm{~ms}$ period in which the cue placeholders faded in to the suppressed eye. Colored cues were then presented to the suppressed eye for $150 \mathrm{~ms}$. All placeholders thickened, and on cuepresent trials one of the four placeholders changed color so that it either matched the target color (target-colored cue) or was a distractor color (distractor-colored cue). In the immediately following target display, each of the four T shapes took on a unique color (red, blue, green, or yellow) for 1,500 ms or until response. Participants first indicated the orientation of the target $\mathrm{T}$ shape as quickly and as accurately as possible, and then reported, without time pressure, their perception of the cue on a scale from 0 (not aware of the cue) to 3 (clearly aware of the cue). (Color figure online) 
cue on approximately half of the trials only (as found by Lamy et al., 2015, and confirmed in the current study following pilot testing). Cues did not predict the target location, and either matched the target color or appeared in a distractor color instead. The observers' task was to identify the orientation of the target-colored $\mathrm{T}$ shape (left or right) and indicate their response via a key press. Following this response, observers provided a subjective report of their perception of the cue, using a scale from 0 (not aware) to 3 (clearly visible). Observers were informed that on some trials no cue would be presented.

Stimuli were displayed against a black background (CIE: $\left..304, .259,1.4 \mathrm{~cd} / \mathrm{m}^{2}\right)$. During the entire presentation, two white (CIE: $.305, .389,214 \mathrm{~cd} / \mathrm{m}^{2}$ ) fixation crosses and two gray (CIE: $.305, .389,59 \mathrm{~cd} / \mathrm{m}^{2}$ ) and white (CIE: .305, .389, $\left.214 \mathrm{~cd} / \mathrm{m}^{2}\right)$ striped squares $\left(7.3^{\circ} \times 7.3^{\circ} \times .2^{\circ}\right.$ of visual angle $)$ were presented on each side of the screen, such that one fixation dot and one square was visible to each eye. The task consisted of a fixation display, a cue display, and a target display.

The fixation display (500 ms) was presented to one eye (pseudorandomly to the left or right eye on each trial) and consisted of a central fixation cross (CIE: .305, .389, $214 \mathrm{~cd} /$ $\left.\mathrm{m}^{2} ; 0.5^{\circ} \times 0.5^{\circ}\right)$ surrounded by four peripheral circles (CIE: $.305, .389,214 \mathrm{~cd} / \mathrm{m}^{2} ; 1$ pixel thick; $1^{\circ}$ radius and $2.5^{\circ}$ from fixation). These circles were placed at the top, bottom, left, and right of the fixation cross. The peripheral circles appeared gradually from $0 \%$ contrast to $100 \%$ contrast over the $500-\mathrm{ms}$ fixation display. The mask was presented to the other eye at 20 $\mathrm{Hz}$. Each masking display was made of circles of various sizes ( $.5^{\circ}$ to $1.5^{\circ}$ radius) and shades of gray (light gray CIE: .299, $.399,107 \mathrm{~cd} / \mathrm{m}^{2}$; dark gray CIE: $.276, .342, .2 \mathrm{~cd} / \mathrm{m}^{2}$; middark gray CIE: $.254, .479,6.0 \mathrm{~cd} / \mathrm{m}^{2}$; mid-gray CIE: .277 , $.446,48.3 \mathrm{~cd} / \mathrm{m}^{2}$ ). Four T shapes (CIE: $.305, .389,214 \mathrm{~cd} /$ $\left.\mathrm{m}^{2} ; 0.5^{\circ} \times 0.5^{\circ}\right)$, two oriented $90^{\circ}$ to the left and two $90^{\circ}$ to the right, were superimposed on the masks.

In the cue display $(150 \mathrm{~ms})$, the peripheral circles thickened (two pixels thick). On cue-present trials, one circle changed color (red, CIE: .607, .365, $43 \mathrm{~cd} / \mathrm{m}^{2}$; green, CIE: .294, $.651,158 \mathrm{~cd} / \mathrm{m}^{2}$; blue, CIE: .144, .083, $17 \mathrm{~cd} / \mathrm{m}^{2}$; or yellow, CIE: $.396, .561,198 \mathrm{~cd} / \mathrm{m}^{2}$ ). The target color was consistent throughout the experiment. For observers searching for a red or green target, cues were either red ( $40 \%$ of trials), green ( $40 \%$ of trials), or no cue was presented (20\% of trials). For observers searching for blue or yellow targets, cues were either blue ( $40 \%$ of trials), yellow ( $40 \%$ of trials), or no cue was presented (20\% of trials). During the target display, T shapes changed color, such that each $\mathrm{T}$ was rendered in a different color (red, CIE: 607, .365, $43 \mathrm{~cd} / \mathrm{m}^{2}$; green, CIE: .294, $.651,158 \mathrm{~cd} / \mathrm{m}^{2}$; blue, CIE: .144, .083, $17 \mathrm{~cd} / \mathrm{m}^{2}$; or yellow, CIE: $.396, .561,198 \mathrm{~cd} / \mathrm{m}^{2}$ ).

On $25 \%$ of cue trials, the target-colored cue was presented in the same location as the target (valid trials), and on $75 \%$ of trials, the target-colored cue was presented in a different location (invalid trials). Thus, the cue display did not predict the location of the target. Participants performed a practice block of 32 trials. During the practice block, performance was monitored to ensure participants understood the task. If required, feedback was provided verbally. Following the practice block, participants performed 10 blocks of 64 trials (for a total of 640 experimental trials; 240 more experimental trials than in Lamy et al., 2015)

\section{Results}

Five participants were excluded from the analysis because they reported that they were consciously aware of the cue on fewer than $10 \%$ of trials. Data from the remaining 22 participants were included in the final analyses. Awareness ratings are presented in Table 1. In line with Lamy et al. (2015), we grouped cue-present trials rated 1,2, and 3 together to form the aware trials and those rated 0 as the unaware trials. Thus, participants were aware of the cue on approximately half of cue-present trials.

Figure 2 shows mean correct RTs as a function of awareness (aware or unaware), cue type (target-colored cue or distractorcolored cue), and cue validity (valid or invalid). We conducted a 2 (awareness) $\times 2$ (cue type) $\times 2$ (cue validity) ANOVA on mean correct RTs. Results revealed a significant main effect of awareness, $F(1,21)=26.294, p=.0 .00004, \mathrm{n}_{\mathrm{p}}{ }^{2}=.556, \mathrm{BF}_{10}=$ $1.637 \mathrm{e}+10$ (Bayesian analysis performed with JASP: Version 0.8.0.0, https://jasp-stats.org/). Mean correct RTs were faster when participants were unaware of the cue $(M=732 \mathrm{~ms}, S D=$ $67 \mathrm{~ms})$ than when they were aware of the cue $(M=793 \mathrm{~ms}, S D=$ $82 \mathrm{~ms}$ ). We ran an additional analysis that included all four awareness levels and found that RTs increased as cue awareness increased, $F(3,54)=16.73, p<.00001$.

The main effects of cue type, $F(1,21)=3.591, p=.072, \mathrm{n}_{\mathrm{p}}{ }^{2}=$ $.146, \mathrm{BF}_{10}=.371$, and cue validity, $F(1,21)=.725, p=.404, \mathrm{\eta}_{\mathrm{p}}{ }^{2}$ $=.033, \mathrm{BF}_{10}=.191$, did not reach significance. Importantly, however, there was a significant two-way interaction between cue type and cue validity, $F(1,21)=30.619, p=.00002, \mathrm{\eta}_{\mathrm{p}}{ }^{2}=$ $.593, \mathrm{BF}_{\text {inclusion }}=772.99$. In line with previous work on featurebased cueing effects (e.g., Folk \& Remington, 1999; Folk et al., 1992; Folk et al., 1994; Gibson \& Amelio, 2000; Gibson \& Kelsey, 1998; Yantis \& Egeth, 1999), there was a samelocation benefit for target-colored cues, such that RTs were faster when target-colored cues were presented in the same location as targets $(M=737 \mathrm{~ms}, S D=70 \mathrm{~ms})$ than when they were presented in a different location $(M=776 \mathrm{~ms}, S D=77 \mathrm{~ms}), t(21)=-3.671$, $p=.001, d=-.783, \mathrm{BF}_{10}=24.779$. Results also revealed a samelocation cost for distractor-colored cues. RTs were slower when cues were presented in the same location as the target $(M=783$ $\mathrm{ms}, S D=83 \mathrm{~ms}$ ) than when they were presented in a different location $(M=755 \mathrm{~ms}, S D=75 \mathrm{~ms}), t(21)=3.933, p=.0008, d=$ $.839, \mathrm{BF}_{10}=43.694$. 
Table 1 Awareness ratings for cue-absent and cue-present trials in Experiments 1-3

\begin{tabular}{|c|c|c|c|c|c|c|}
\hline & \multicolumn{2}{|c|}{ Experiment 1} & \multicolumn{2}{|c|}{ Experiment 2} & \multicolumn{2}{|c|}{ Experiment 3} \\
\hline & Cue absent & Cue present & Cue absent & Cue present & Cue absent & Cue present \\
\hline 0 & $69 \%$ & $49 \%$ & $83 \%$ & $41 \%$ & $67 \%$ & $44 \%$ \\
\hline Unaware & $69 \%$ & $49 \%$ & $83 \%$ & $41 \%$ & $67 \%$ & $44 \%$ \\
\hline 1 & $14 \%$ & $13 \%$ & $9 \%$ & $13 \%$ & $15 \%$ & $15 \%$ \\
\hline 2 & $9 \%$ & $14 \%$ & $4 \%$ & $11 \%$ & $6 \%$ & $8 \%$ \\
\hline 3 & $9 \%$ & $25 \%$ & $5 \%$ & $34 \%$ & $13 \%$ & $33 \%$ \\
\hline Aware & $32 \%$ & $52 \%$ & $18 \%$ & $\mathbf{5 8 \%}$ & $33 \%$ & $56 \%$ \\
\hline
\end{tabular}

The other two-way interactions did not reach significance, awareness and cue validity, $F(1,21)=1.251, p=.276, \mathrm{\eta}_{\mathrm{p}}{ }^{2}=$ $.056, \mathrm{BF}_{\text {inclusion }}=.498$; awareness and cue type, $F(1,21)=$ $.169, p=.685, \mathrm{\eta}_{\mathrm{p}}{ }^{2}=.008, \mathrm{BF}_{\text {inclusion }}=.756$. Finally, the threeway interaction between awareness, cue type, and cue validity did not reach significance, $F(1,21)=.171, p=.683, \mathrm{\eta}_{\mathrm{p}}{ }^{2}=$ $.008, \mathrm{BF}_{\text {inclusion }}=.244$, suggesting that the same-location benefit for target-colored cues and the same-location cost for distractor-colored cues were not differentially affected by awareness.

An analogous ANOVA on error rates (see Table 2) revealed a significant main effect of awareness, $F(1,21)=$ $5.758, p=.026, \mathrm{\eta}_{\mathrm{p}}^{2}=.215, \mathrm{BF}_{10}=2,441.679$. Mean error rates were higher when participants were aware of the cue $(M=16.31 \%, S D=16.72)$ than when they were unaware of the cue $(M=10.21 \%, S D=9.57)$. None of the other main effects or interactions reached significance, suggesting there was no speed-accuracy trade-off. Main effect of cue type, $F(1,21)=.905, p=.352, \eta_{\mathrm{p}}^{2}=.041, \mathrm{BF}_{10}=$ .213; main effect of cue validity, $F(1,21)=2.879, p=$ $.105, \mathrm{\eta}_{\mathrm{p}}^{2}=.121, \mathrm{BF}_{10}=.231$; Awareness $\times$ Cue Type, $F(1,21)=.208, p=.653, \eta_{\mathrm{p}}^{2}=.010, \mathrm{BF}_{\text {inclusion }}=.103$; Awareness $\times$ Cue Validity, $F(1,21)=.558, p=.463, \mathrm{\eta}_{\mathrm{p}}{ }^{2}=$ $.026, \mathrm{BF}_{\text {inclusion }}=.108 ;$ Cue Type $\times$ Cue Validity, $F(1,21)$ $=2.228, p=.150, \mathrm{n}_{\mathrm{p}}^{2}=.096, \mathrm{BF}_{\text {inclusion }}=.032$; Awareness $\times$ Cue Type $\times$ Cue Validity, $F(1,21)=.031, p=.862, \mathrm{n}_{\mathrm{p}}{ }^{2}=$ $.001, \mathrm{BF}_{\text {inclusion }}=.004$.

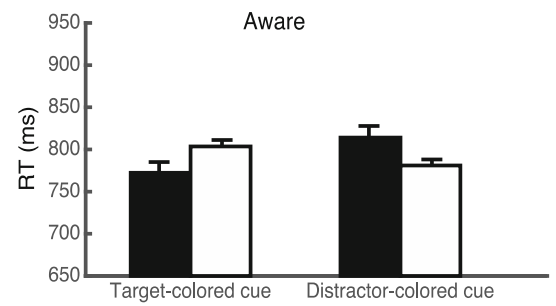

Fig. 2 Mean correct RTs to targets in Experiment 1, shown as a function of cue color, cue condition, and cue awareness. Cue color either matched the target color (target-colored cue) or was a distractor color (distractorcolored cue). Cue location either matched the target location (valid) or was different from the target location (invalid). The aware condition included trials in which participants reported having some awareness of the

\section{Discussion}

The results from Experiment 1 demonstrate that attention can be oriented to task-relevant cues even when those cues are not consciously perceived, and that the magnitude of this orienting effect is largely independent of cue awareness. Task-irrelevant cues caused a same-location cost. Interestingly, the magnitude of the cost was also independent of cue awareness, a finding that is not consistent with Lamy et al. (2015), who found a same-location cost for aware cues, but not for unaware cues (see, however, Schoeberl et al., 2018). Given that we used the same methodological design as Lamy et al., this finding is surprising. Having said this, the same location cost for unaware cues is a small effect. Thus, as we used a larger sample and had observers perform more trials than did Lamy et al., our results likely reflect that we simply had more statistical power to uncover this small effect.

In Experiment 1, feature-based cueing effects were operationalized in terms of RT differences between valid and invalid cues. Response times, however, represent the final outcome of several information-processing stages, from initial encoding and selection of sensory inputs to response execution (Schmidt, 1988). It is possible that some of these processes are modulated by cue awareness, while others remain largely independent of it. We investigated this possibility in Experiment 2 by comparing neural activity associated with consciously perceived versus unperceived cues.

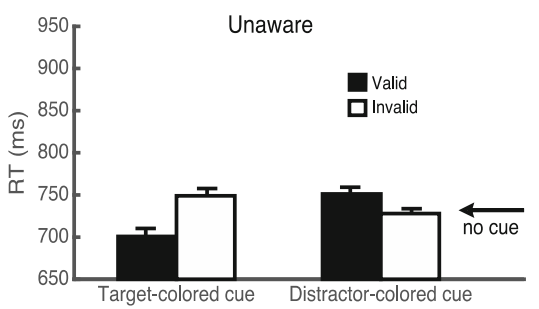

cue (i.e., awareness ratings of 1,2, or 3). The unaware condition included only those trials in which participants indicated they were not aware of the cue (i.e., an awareness rating of 0 ). The small arrow on the right indicates the mean reaction time for the no-cue condition. Error bars represent within-subjects standard errors of the mean 
Table 2 Mean reaction times and error rates for the different cue color and awareness conditions of Experiment 1

\begin{tabular}{|c|c|c|c|c|c|c|c|c|}
\hline \multirow[t]{3}{*}{ Cue validity } & \multicolumn{4}{|c|}{ Target-colored cue } & \multicolumn{4}{|c|}{ Distractor-colored cue } \\
\hline & \multicolumn{2}{|l|}{ Unaware } & \multicolumn{2}{|l|}{ Aware } & \multicolumn{2}{|l|}{ Unaware } & \multicolumn{2}{|l|}{ Aware } \\
\hline & $\mathrm{RT}(\mathrm{ms})$ & Error rate $(\%)$ & $\mathrm{RT}(\mathrm{ms})$ & Error rate $(\%)$ & $\mathrm{RT}(\mathrm{ms})$ & Error rate $(\%)$ & $\mathrm{RT}(\mathrm{ms})$ & Error rate $(\%)$ \\
\hline Valid & $701(16)$ & $9.0(2.6)$ & $772(19)$ & $16.4(4.0)$ & $751(15)$ & $12.0(2.6)$ & $814(24)$ & $18.0(4.2)$ \\
\hline Invalid & 749 (17) & $9.8(2.1)$ & $804(18)$ & $15.7(3.6)$ & $728(15)$ & $10.1(2.5)$ & $781(19)$ & $15.2(3.5)$ \\
\hline
\end{tabular}

Note. Standard errors are given in parentheses

\section{Experiment 2}

In Experiment 2, we employed EEG to examine the timing and magnitude of cue-related evoked responses in an analogous feature-based cueing paradigm to that employed in Experiment 1 . We focused our analyses on the N2pc component, consistent with previous investigations of spatial orienting (Eimer, 1996; Kiss et al., 2008; Luck \& Hillyard, 1994; Woodman \& Luck, 1999, 2003b).

\section{Method}

\section{Participants}

Twenty new individuals participated in Experiment 2 (17 females, mean age $=21.00$ years, $S D=1.00$ ).

\section{Apparatus, stimuli, and procedure}

The stimuli and procedure were similar to those of Experiment 1, except for the following changes. Our aim in Experiment 2 was to measure an N2pc to the cue displays. Thus, to accommodate the measurement of $\mathrm{N} 2 \mathrm{pc}$ responses, all cue and target stimuli $\left(.05^{\circ} \times .05^{\circ}\right)$ were lateralized so that they appeared at the top left, bottom left, top right, and bottom right corners ( $2.5^{\circ}$ distant from fixation; see Fig. 3$)$ of the display. Cuepresent trials consisted of a target-colored cue, a distractorcolored cue, and two neutral cues. As in Experiment 1, target and distractor colors were consistent throughout the experiment. For observers searching for red or green targets, cues were red or green. For observers searching for blue or yellow targets, cues were blue or yellow. To ensure that any cuerelated N2pc response was driven by top-down attentional biasing and not by stimulus differences, target-colored cues and distractor-colored cues were always presented in opposite hemifields (left/right). Target displays consisted of one targetcolored T, one distractor-colored T, and two white Ts. As with the cue display, each hemifield contained one colored $\mathrm{T}$ shape (target or distractor). The CFS mask was presented at 20 or $22 \mathrm{~Hz}$ (10 participants each). Participants completed 12 blocks of 64 trials (for a total of 768 experimental trials; 368 more than in Lamy et al., 2015).
For observers searching for red or green targets, one cue was red and one cue was green (640 trials; $83 \%$ ), or no cue was presented (128 trials; 17\%). For observers searching for blue or yellow targets, one cue was blue and one cue was yellow (640 trials; $83 \%$ ), or no cue was presented (128 trials; $17 \%)$. During the target display, two T shapes changed color. For participants searching for red or green, one $\mathrm{T}$ shape was red (CIE: 607, .365, $43 \mathrm{~cd} / \mathrm{m}^{2}$ ) and one was green (CIE: .294,

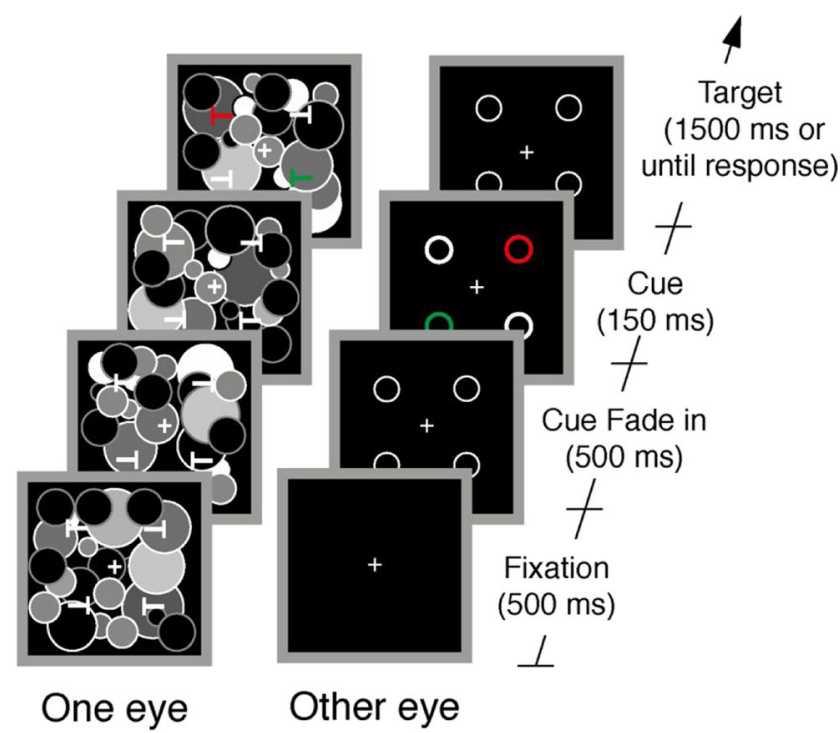

Fig. 3 Schematic of individual trial events in Experiment 2. Participants' task was to report the orientation of the target $\mathrm{T}$ shape and to indicate whether they were aware of a colored cue. A flickering mask display ( 20 or $22 \mathrm{~Hz}$ ) and four white $\mathrm{T}$ shapes (two rotated $90^{\circ}$ clockwise and two rotated $90^{\circ}$ counterclockwise) were presented to one eye throughout the experiment. Each trial began with a $500-\mathrm{ms}$ fixation cross, followed by a 500 -ms period in which the cue placeholders faded in to the suppressed eye. Colored cues were then presented to the suppressed eye for $150 \mathrm{~ms}$. All placeholders thickened, and on cue-present trials, two of the four placeholders changed color so that one matched the target color (targetcolored cue) and another matched the distractor color (distractor-colored cue). Neutral cues remained white. These colored circles were always presented in different hemifields. In the immediately following target display, two of the four $\mathrm{T}$ shapes changed color such that one matched the target color (target) and another was the distractor target (distractor). The target display was presented for $1,500 \mathrm{~ms}$ or until response. Participants first indicated the orientation of the target $T$ shape as quickly and as accurately as possible, and then reported, without time pressure, their perception of the cue on a scale from 0 (not aware of the cue) to 3 (clearly aware of the cue). (Color figure online) 
$.651,158 \mathrm{~cd} / \mathrm{m}^{2}$ ). For participants searching for blue or yellow, one T shape was blue (CIE: .144, .083, $17 \mathrm{~cd} / \mathrm{m}^{2}$ ) and one was yellow (CIE: $.396, .561,198 \mathrm{~cd} / \mathrm{m}^{2}$ ). The other two T shapes remained white.

Electroencephalography EEG data were recorded continuously from 64 active $\mathrm{Ag} / \mathrm{AgCl}$ scalp electrodes. The electrodes were arranged according to the international standard 10-10 system for electrode placement (Oostenveld \& Praamstra, 2001) using a nylon cap. Eye movements were monitored using bipolar horizontal and vertical electrooculography (EOG). EEG and EOG signals were amplified by Biosemi Active Two amplifiers and sampled at $1024 \mathrm{~Hz}$ with 24-bit A/D conversion. Standard reference and ground electrodes were used during recording.

Off-line preprocessing of the EEG data was performed using Brain Electrical Source Acquisition (BESA 5.3; MEGIS Software GmbH, Gräfelfing, Germany). Noisy channels were identified via visual inspection and replaced by interpolation of the voltages recorded at all other scalp electrodes. A maximum of four electrodes were interpolated for each participant. Data were then subjected to a $0.1 \mathrm{~Hz}$ highpass filter and a $100 \mathrm{~Hz}$ low-pass filter. The data were rereferenced to the average of all 64 scalp electrodes and segmented into 1-s epochs spanning $200 \mathrm{~ms}$ before cue onset to $800 \mathrm{~ms}$ after cue onset. The average voltage in the 200-ms precue interval was used as a baseline for each epoch. Epochs with excessive noise from eye blinks or other muscle activity were identified by visual inspection and rejected from further analysis. An average of $18 \%$ of epochs were rejected using this criterion, with no more than $25 \%$ rejected for any individual participant. Incorrect trials were also excluded from the analysis. The remaining epochs were averaged for each participant separately for each condition.

The N2pc response to the cue was quantified within the time period of 200-300 ms after cue onset. This time window was chosen to match that of Lien, Ruthruff, Goodin, and Remington (2008), who conducted a similar experiment (but without the awareness manipulation), and is also consistent with those adopted in previous research on the N2pc (e.g., Eimer, 1996; Hopf et al., 2006b; Luck \& Hillyard, 1994; Wascher \& Wauschkuhn, 1996; Wauschkuhn et al., 1998). The N2pc was calculated as the mean amplitude from electrodes contralateral to the target-colored cue minus the mean amplitude for the homologous electrodes ipsilateral to the target-colored cue. To determine electrode sites for analysis, we calculated the average response for each electrode site during the cue-related time window, separately for trials in which the target-colored cue was presented in the right visual hemifield and trials in which the target-colored cue was presented in the left visual hemifield. We then collapsed across hemispheres such that responses contralateral to the targetcolored cue were represented in the right hemisphere and responses ipsilateral to the target-colored cue were represented in the left. We chose the three electrode sites with the highest responses in the right hemisphere $(\mathrm{P} 8, \mathrm{P} 10$, and $\mathrm{PO} 8)$ and the homologous electrode sites in the left hemisphere (P7, P9, PO7) for analysis.

\section{Results}

\section{Behavioral analysis}

The behavioral results from Experiment 2 replicated those of Experiment 1. Awareness ratings can be seen in Table 1. We found faster RTs to targets that were validly cued by targetcolored cues than by neural cues. This pattern of results was found for both aware and unaware target-colored cues. We also found slower RTs to targets that were validly cued by distractor-colored cues than by neutral cues. This pattern of results was found for both aware and unaware distractorcolored cues. Again, we grouped cue-present trials rated 1, 2 , and 3 to form the aware trials, and those rated 0 as the unaware trials.

Figure 4 shows mean correct RTs as a function of awareness (aware or unaware) and cue condition (target-colored cue in target location, distractor-colored cue in target location, or neutral cue in target location). To analyze these patterns statistically, we conducted a 2 (awareness) $\times 3$ (cue condition) repeated-measures ANOVA on mean correct RTs (see Table 2). Results revealed a significant main effect of awareness, $F(1,19)=26.444, p=.00006, \mathrm{n}_{\mathrm{p}}{ }^{2}=.582, \mathrm{BF}_{10}=$ $9.274 \mathrm{e}+6$. Mean correct RTs were faster for unaware trials

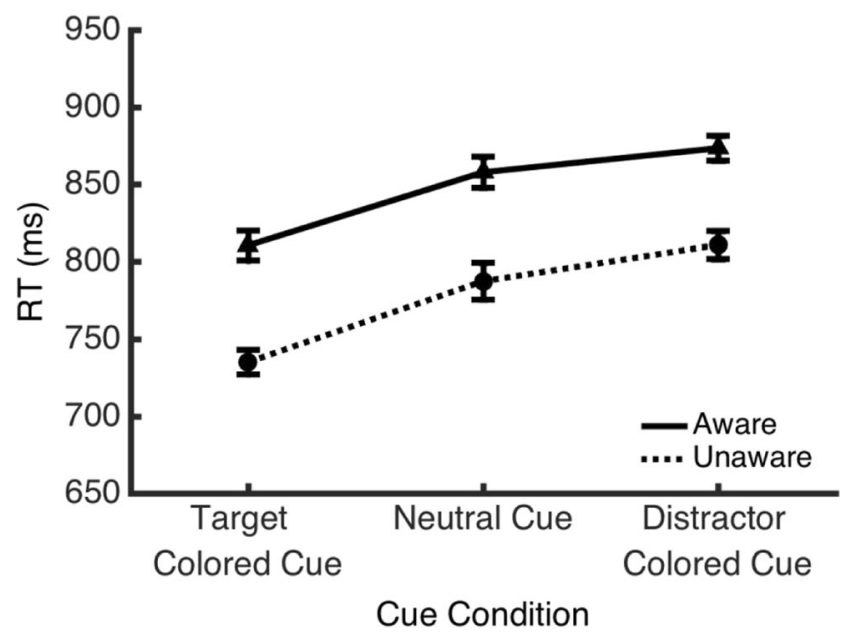

Fig. 4 Mean correct RTs to targets in Experiment 2, shown as a function of cue condition and cue awareness. Target location either matched the target-colored-cue location (target-colored cue), the distractor-coloredcue location (distractor-colored cue), or a neutral cue location (neutral cue). The aware condition included trials in which participants reported having some awareness of the cue. By contrast, the unaware condition included only those trials in which participants indicated they were not aware of the cue. Error bars represent within-subjects standard errors of the means 
$(M=778 \mathrm{~ms}, S D=115)$ than for aware trials $(M=847 \mathrm{~ms}, S D$ $=111)$. There was also a significant main effect of cue condition, $F(2,38)=27.429, p=.00000004, \mathrm{n}_{\mathrm{p}}{ }^{2}=.591, \mathrm{BF}_{10}=$ $4,419.50$. Follow-up tests using Bonferroni correction revealed that RTs were faster when targets were presented in the same location as the target-colored cue $(M=773 \mathrm{~ms}, S D$ $=104)$ than when they were presented in a neutral cue location $(M=823 \mathrm{~ms}, S D=118), t(19)=-4.743, p=.0001, d=$ $\left.-1.060, \mathrm{BF}_{10}=204.13\right)$. Furthermore, RTs were slower when distractor-colored cues were presented in the same location as the target $(M=842 \mathrm{~ms}, S D=122)$ than when they were presented in the location of a neutral-colored cue, $t(19)=$ $3.811, p=.001, d=.852, \mathrm{BF}_{10}=31.69$. The interaction between awareness and cue condition was not significant, $F(2$, $38)=.496, p=.530$ (Greenhouse-Geisser corrected), $\mathrm{\eta}_{\mathrm{p}}{ }^{2}=$ $.025, \mathrm{BF}_{\text {inclusion }}=.615$, suggesting that the effect of cue condition did not depend on awareness. Thus, top-down attentional settings were involved in feature-based cueing even when cues were not consciously perceived.

A further ANOVA on error rates (see Table 3) revealed no significant main effect of awareness, $F(1,19)=.182, p=.675$, $\eta_{\mathrm{p}}{ }^{2}=.009, \mathrm{BF}_{10}=.270$, but a significant main effect of cue condition, $F(2,38)=5.823, p=.006, \eta_{\mathrm{p}}{ }^{2}=.235, \mathrm{BF}_{10}=.670$. Follow-up tests using Bonferroni correction revealed that the main effect of cue condition was driven by a significantly higher mean error rate for trials in which the target was located in the distractor-colored-cue location $(M=9.40 \%, S D=6.21)$ than for trials in which the target was located in the targetcolored-cue location $(M=7.21 \%, S D=6.38), t(19)=-3.462$, $p=.003, d=-.774, \mathrm{BF}_{10}=15.948$. The interaction between awareness and cue condition was also significant, $F(2,38)=$ $5.328, p=.009, \mathrm{\eta}_{\mathrm{p}}{ }^{2}=.219, \mathrm{BF}_{\text {inclusion }}=.180$. This significant interaction was followed up by evaluating the simple main effects of cue condition separately for aware and unaware trials. Mean error rates did not differ between cue conditions for aware trials, $F(2,38)=1.172, p=.321, \mathrm{\eta}_{\mathrm{p}}{ }^{2}=.058$, but they did differ significantly between cue condition for unaware trials, $F(2,38)=11.71, p=.0001, \eta_{\mathrm{p}}{ }^{2}=.381$. We performed follow-up $t$ tests with Bonferroni correction, to assess these differences. For unaware cues, error rates were significantly lower when targets were located in the same location as targetcolored cues $(M=5.85 \%, S D=4.39)$ than when targets were located in the same location as distractor-colored cues $(M=$ $9.52 \%, S D=5.36), t(19)=-4.144, p=.0006, d=.927, \mathrm{BF}_{10}=$ 61.551 , or when targets were located in the same location as neutral cues $(M=8.55 \%, S D=5.47), t(19)=-3.203, p=.005$, $d=-.716, \mathrm{BF}_{10}=.9 .694$. Thus, the interaction between awareness and cue condition appears to be driven by fewer errors in the unaware target-colored-cue condition. Overall these results suggest there was no speed-accuracy trade-off in Experiment 2.

\section{ERP analysis}

As we were interested in the effect of awareness on the neural signatures of attentional orienting, we focused our ERP analyses on cue-related responses. The ERP data were analyzed as a function of cue awareness (aware or unaware) and electrode laterality (contralateral or ipsilateral to the target-colored cue location). An N2pc component was evident for both aware and unaware trials, but with a slightly larger negative amplitude for the aware trials (see Fig. 5). ERP data for the cuerelated response were submitted to a 2 (awareness) $\times 2$ (electrode laterality) repeated-measures ANOVA on the mean response during the cue-related N2pc time window.

There was a significant main effect of awareness on cueevoked ERP magnitude, $F(1,19)=10.14, p=.005, \eta_{\mathrm{p}}{ }^{2}=$ $.348, \mathrm{BF}_{10}=11.330$. Responses were more negative for aware trials $(M=-.968, S D=1.109)$ than for unaware trials $(M=$ $-.520, S D=1.384)$. There was also a significant main effect of electrode laterality, $F(1,19)=20.65, p=.0002, \eta_{\mathrm{p}}{ }^{2}=.521$, $\mathrm{BF}_{10}=1,293.948$. Responses at electrode sites contralateral to the target-colored cue (ipsilateral to distractor-colored cue) were more negative $(M=-1.062, S D=1.325)$ than responses at electrode sites ipsilateral to the target-colored cue (contralateral to distractor-colored cue; $M=-.426, S D=1.178$ ), indicating a significant N2pc response. Critically, there was also a significant interaction between awareness and electrode laterality, $F(1,19)=13.66, p=.002, \mathrm{\eta}_{\mathrm{p}}{ }^{2}=.418, \mathrm{BF}_{\text {inclusion }}=$ 3.310. To investigate whether there was an N2pc to both aware and unaware trials, we followed up this interaction with pairwise $t$ tests. When participants were aware of the cue, mean ERPs were significantly more negative at electrode sites contralateral to the target-colored-cue location $(M=-1.384$,

Table 3 Mean reaction times and error rates for the different cue and awareness conditions of Experiment 2

\begin{tabular}{|c|c|c|c|c|}
\hline \multirow[t]{2}{*}{ Cue condition } & \multicolumn{2}{|l|}{ Unaware } & \multicolumn{2}{|l|}{ Aware } \\
\hline & $\mathrm{RT}(\mathrm{ms})$ & Error rate $(\%)$ & RT (ms) & Error rate $(\%)$ \\
\hline Target-colored cue & $735(24)$ & $5.8(1.0)$ & $810(24)$ & $8.6(2.2)$ \\
\hline Distractor-colored cue & $811(30)$ & $9.5(1.2)$ & $874(28)$ & $9.3(1.9)$ \\
\hline Neutral & $787(27)$ & $8.5(1.2)$ & $858(27)$ & $7.9(1.6)$ \\
\hline
\end{tabular}

Note. Standard errors are given in parentheses 


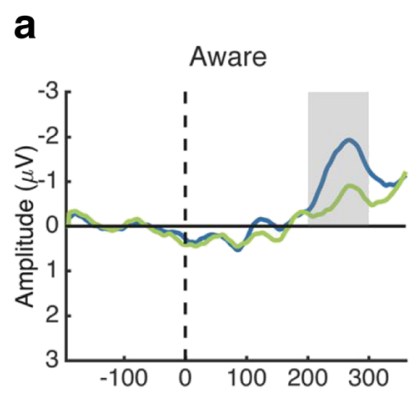

b

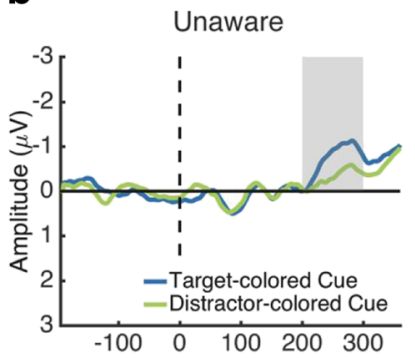

C

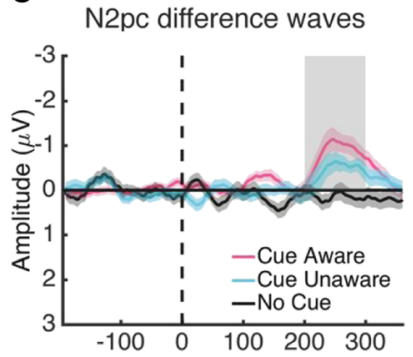

Fig. 5 Grand average event-related potentials (ERPs) for target-colored cues, averaged across posterior electrode sites (P7/P8, P9/P10, PO7/PO8) contralateral to the target-colored cue location (blue) and distractor colored cue location (green), as a function of awareness (aware vs. unaware). a Average ERPs when participants were aware of the cue. b Average ERPs when participants were unaware of the cue. c Difference waves calculated by subtracting ipsilateral from contralateral ERPs for the aware (magenta), unaware (cyan), and no-cue trials (black), showing the cueinduced N2pc. Cue onset is at time zero. Shaded areas represent analyzed

$S D=1.204)$ than at electrode sites ipsilateral to the targetcolored-cue location $(M=-.553, S D=1.181), t(19)=$ $-5.206, p=.00005, d=-1.164, \mathrm{BF}_{10}=514.330$. Critically, this pattern was also found for unaware trials. When participants were unaware of the cue, mean ERPs were significantly more negative at electrode sites contralateral to the targetcolored-cue location $(M=-.740, S D=1.580)$ than responses at electrode sites ipsilateral to the target-colored-cue location $(M=-.300, S D=1.315), t(19)=-3.172, p=.005, \mathrm{~d}=-.709$, $\mathrm{BF}_{10}=9.136$. Thus, there was a significant $\mathrm{N} 2 \mathrm{pc}$ to targetcolored cues both when participants were aware of the cue and also when the cue was not consciously perceived; however, the magnitude of the N2pc was greater for aware cues (mean difference $=-.805, S D=.598$ ) than for unaware cues (mean difference $=-.428, S D=.514$; see Fig. $5 \mathrm{c}$ ).

The difference in N2pc magnitude between aware and unaware cues was driven by a larger negative response at electrode sites contralateral to aware target-colored cues than those contralateral to unaware target-colored cues, $t(19)=$ $-4.082, p=.0006, d=-.913, \mathrm{BF}_{10}=514.330$. Responses at electrode sites contralateral to the distractor-colored cue (ipsilateral to the target colored cue) did not differ between aware and unaware conditions, $t(19)=-1.771, p=.093, d=-.396$, $\mathrm{BF}_{10}=9.136$. Thus, the difference in N2pc magnitude between aware and unaware cues was likely driven by differences between processing aware and unaware target-colored cues, but not between aware and unaware distractor-colored cues.

\section{Discussion}

In Experiment 2 we recorded EEG while participants performed a behavioral task with stimuli and design similar to that used in Experiment 1. We found an RT benefit for valid versus invalid target-colored cues, with no difference in the time window for the cue-related response (200-300 ms after cue onset). Data have been smoothed using a sliding boxcar for display only. All analyses were performed on the unsmoothed data. Note that here the label Target-colored cue represents responses that were contralateral to the target-colored cue, but also ipsilateral to the distractor-colored cue; likewise, the label distractor-colored cue represents responses that were contralateral to the distractor-colored cue, but also ipsilateral to the targetcolored cue. (Color figure online)

magnitude of this feature-based cueing effect for cue-aware and cue-unaware trials. These findings are consistent with our Experiment 1 findings and those of Lamy et al. (2015). We also found an RT cost for valid versus invalid distractorcolored cues. We found no difference in the magnitude of this same location cost for cue-aware and cue-unaware trials. Our finding that the same location cost does not depend on awareness aligns with recent research by Schoeberl et al. (2018), in which the authors found that valid cues that mismatched the observers' goals produced a same location cost for unaware cues.

The ERP data revealed an N2pc response to both aware and unaware cues. The N2pc is thought to reflect target enhancement (Eimer, 1996; Shedden \& Nordgaard, 2001). Thus, the results from Experiment 2 suggest that attention was allocated to the location of items that share features with observers' task goals even in the absence of awareness. ${ }^{1}$ Interestingly, the magnitude of the N2pc response in Experiment 2 was larger for cue-aware trials than for cue-unaware trials. This magnitude difference was driven by a larger negative response at electrode sites contralateral to aware target-colored cues than those contralateral to unaware target-colored cues. Responses at electrode sites contralateral to the distractor-colored cue did not differ between aware and unaware cues. Thus, our findings suggest that neural measures of target processing are modulated by awareness, but those associated with distractor suppression are not $-\mathrm{a}$ finding that is reversed in relation to the behavioral results reported in Lamy et al. (2015).

\footnotetext{
${ }^{1}$ There was no N2pc in no-cue trials $(p>.05)$. Thus, there was a neural difference between unaware cue-present trials and unaware no-cue trials. It might be argued that participants' actual level of awareness, as indexed by subjective ratings, differed between unaware cue-present and unaware cueabsent trials. In interpreting the awareness ratings, however, we followed the reasoning of Lamy et al. (2015) and took the participants' subjective awareness ratings in the cue-present trials at face value - that is, when participants gave a zero rating, we defined their experience as unaware of the cue.
} 
In Experiment 2, each trial involved the presentation of a target-colored cue in one hemifield and a distractor-colored cue in the opposite hemifield. We reasoned that by using these balanced displays, any lateralized effects would be attributable to influences from participants' current task set as opposed to stimulus-driven effects. There was, however, a downside to using such a balanced-display design. As the N2pc is by definition a difference between contralateral and ipsilateral responses, the balanced displays used in Experiment 2 may have yielded N2pc waveforms that reflected a combination of responses elicited by the target-colored cue and the simultaneously presented distractor-colored cue. Consistent with this, Hickey, Di Lollo, and McDonald (2009) have suggested that the N2pc is a combination of two ERP components: the $\mathrm{N}_{\mathrm{T}}$, a negative ERP component associated with target enhancement, and the $\mathrm{P}_{\mathrm{D}}$, a positive ERP component associated with distractor suppression (e.g., Cosman, Lowe, Woodman, \& Schall, 2018; Gaspelin \& Luck, 2018b). Although in Experiment 2 we were able to measure neural responses separately for contralateral and ipsilateral electrode sites, we were not able to determine whether these responses reflected processing of the target-colored cue, the distractor-colored cue, or a combination of both. We sought to address this issue in Experiment 3.

\section{Experiment 3}

While much of the literature on feature-based cueing has focused on attentional allocation in terms of the selective enhancement of task-relevant information (e.g., Wolfe, 1994), suppression of task-irrelevant information is also a key component of selective processes (Braithwaite \& Humphreys, 2003; Lleras, Kawahara, Wan, \& Ariga, 2008). Indeed, a large volume of research supports the idea that selective attention both modulates activity in sensory processing areas by enhancing relevant features (Bisley \& Goldberg, 2010; Corbetta, Miezin, Dobmeyer, Shulman, \& Petersen, 1990; Corbetta \& Shulman, 2002; Desimone \& Duncan, 1995; Fries, Reynolds, Rorie, \& Desimone, 2001; Gruber, Muller, Keil, \& Elbert,1999; Hillyard \& Anllovento, 1998; Kastner, Deweerd, Desimone, \& Ungerleider, 1998; Kastner \& Ungerleider, 2000; Luck, Woodman, \& Vogel, 2000; Raz \& Buhle, 2006; Reynolds \& Chelazzi, 2004; Siegel, Donner, Oostenveld, Fries, \& Engel, 2008; Tallon-Baudry, Bertrand, Henaff, Isnard, \& Fischer, 2005; Treue, 2003) and suppressing irrelevant features (Andersen \& Muller, 2010; Chelazzi, Miller, Duncan, \& Desimone, 1993; Hopf et al., 2006a; Luck, Chelazzi, Hillyard, \& Desimone, 1997; Moran \& Desimone, 1985; Reynolds, Chelazzi, \& Desimone, 1999; Thut, Nietzel, Brandt, \& Pascual-Leone, 2006; Vanduffel, Tootell, \& Orban, 2000; Worden, Foxe, Wang, \& Simpson, 2000). This idea that selection involves both enhancement and suppression is central to prominent theories of attention, such as the biased competition model (Desimone \& Duncan, 1995) and the notion of priority maps (Itti \& Koch, 2001).

In Experiment 3, we tested whether the N2pc response reported in Experiment 2 is the result of an $\mathrm{N}_{\mathrm{T}}$ to the targetcolored cue, a $\mathrm{P}_{\mathrm{D}}$ to the distractor-colored cue, or a combination of both components. The design was similar to that employed in Experiment 2, except that only one cue was presented on each cue-present trial (either a target-colored or a distractor-colored cue). This design allowed us to investigate lateralized neural responses separately for target-colored and distractor-colored cues under aware and unaware conditions. In line with our findings from Experiments 1 and 2, we expected to observe an RT benefit for valid target-colored cues and an RT cost for valid distractor-colored cues, for both aware and unaware trials. For the ERPs, we expected to observe an $\mathrm{N}_{\mathrm{T}}$ to target-colored cues, which would be larger in magnitude for aware trials than for unaware trials. We also predicted a $\mathrm{P}_{\mathrm{D}}$ in response to distractor-colored cues, but not target-colored cues.

\section{Method}

\section{Participants}

Twenty-four new individuals participated in Experiment 3 (12 males, mean age $=21.37$ years, $S D=1.53$ ).

\section{Apparatus, stimuli, and procedure}

The stimuli and procedure were the same as those of Experiment 2, with the following exceptions. To accommodate the measurement of the $\mathrm{N}_{\mathrm{T}}$ and $\mathrm{P}_{\mathrm{D}}$ components, cuepresent trials consisted of a single target-colored cue in one of the four locations, with three neutral cues in the remaining locations (320 trials; 41.67\%), or a single distractor-colored cue in one location with three neutral cues (320 trials; $41.67 \%$ ). In an additional 128 trials (16.67\%), no cue was presented. The CFS mask was presented at $20 \mathrm{~Hz}$ for each participant.

\section{Electroencephalography}

Off-line preprocessing of the EEG data was performed using EEGLAB (Delorme \& Makeig, 2004). Muscle, eye movement, and blink artifacts were identified and removed using independent component analysis. Incorrect trials were also excluded from the analysis. An average of $18 \%$ of epochs were rejected using this criterion, with no more than $25 \%$ rejected for any individual participant. The remaining epochs were averaged for each participant separately for each condition. 
The $\mathrm{N}_{\mathrm{T}}$ responses to the target-colored cue and the $\mathrm{P}_{\mathrm{D}}$ responses to the distractor colored cue were quantified within the time period of 200-300 ms after cue onset. The $\mathrm{N}_{\mathrm{T}}$ was calculated as the mean amplitude from electrodes contralateral to the target-colored cue minus the mean amplitude for the homologous three electrodes ipsilateral to the target-colored cue. The $\mathrm{P}_{\mathrm{D}}$ was calculated as the mean amplitude from electrodes contralateral to the distractor-colored cue minus the mean amplitude for the homologous three electrodes ipsilateral to the distractor-colored cue. To determine electrode sites for analysis, we calculated the average response for each electrode site during the cue-related time window, separately for trials in which the cue was presented in the right visual hemifield and trials in which the cue was presented in the left visual hemifield. We then collapsed across hemispheres such that responses contralateral to the cue were represented in the right hemisphere and responses ipsilateral to the cue were represented in the left. We chose the three electrode sites with the highest responses in the right hemisphere (P8, P10, and PO8) and the homologous electrode sites in the left hemisphere (P7, P9, PO7) for analysis.

\section{Results}

Data from five participants were excluded from the analysis because these individuals reported being aware of the cue on more than $50 \%$ of no-cue trials. Data from the remaining 19 participants were included in the following analyses.

\section{Behavioral analysis}

Awareness ratings are presented in Table 1. As in Experiments 1 and 2, we grouped cue-present trials rated 1, 2, and 3 together to form the aware trials, and those rated 0 as the unaware trials.

Figure 6 shows mean correct RTs as a function of awareness (aware or unaware), cue type (target-colored cue or distractor-colored cue), and cue validity (valid or invalid). We conducted a 2 (awareness) $\times 2$ (cue type) $\times 2$ (cue validity) ANOVA on mean correct RTs (see Table 4 ). There was a

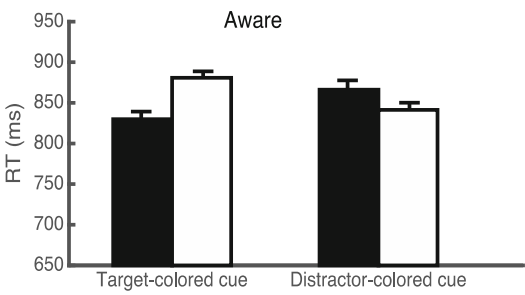

Fig. 6 Mean correct RTs to targets in Experiment 3, shown as a function of cue color, cue condition, and cue awareness. Cue color either matched the target color (target-colored cue) or was a distractor color (distractorcolored cue). Cue location either matched the target location (valid) or was different to the target location (invalid). The aware condition significant main effect of awareness, $F(1,18)=28.473, p=$ $\left..000045 \eta_{\mathrm{p}}{ }^{2}=.613, \mathrm{BF}_{10}=2.464 \mathrm{e}+7\right)$, with mean correct RTs faster when participants were unaware of the cue $(M=796 \mathrm{~ms}$, $S D=117 \mathrm{~ms})$ than when they were aware of the cue $(M=855$ $\mathrm{ms}, S D=109 \mathrm{~ms}$ ).

The main effects of cue type, $F(1,18)=.569, p=.460, \eta_{\mathrm{p}}{ }^{2}$ $=.031, \mathrm{BF}_{10}=.221$, and cue validity, $F(1,18)=4.113, p=$ $.058, \eta_{\mathrm{p}}{ }^{2}=.186, \mathrm{BF}_{10}=.660$, did not reach significance. Again, however, there was a significant two-way interaction between cue type and cue validity, $F(1,18)=26.414, p=$ $.000069, \mathrm{n}_{\mathrm{p}}{ }^{2}=.595, \mathrm{BF}_{\text {inclusion }}=3048.43$. Specifically, there was a same-location benefit for target-colored cues, such that RTs were faster when target-colored cues were presented in the same location as targets $(M=793 \mathrm{~ms}, S D=126 \mathrm{~ms})$ compared with when they were presented in a different location $(M=850 \mathrm{~ms}, S D=124 \mathrm{~ms}), t(18)=-4.192, p=.000548$, $d=-.962, \mathrm{BF}_{10}=62.505$. Results also revealed a samelocation cost for distractor-colored cues. RTs were slower when cues were presented in the same location as the target $(M=840 \mathrm{~ms}, S D=107 \mathrm{~ms})$ than when they were presented in a different location $(M=818 \mathrm{~ms}, S D=117 \mathrm{~ms}), t(18)=2.518$, $p=.021, d=.578, \mathrm{BF}_{10}=2.775$.

The other two-way interactions did not reach significance, awareness and cue type, $F(1,18)=3.591, p=.074, \mathrm{\eta}_{\mathrm{p}}{ }^{2}=.166$, $\mathrm{BF}_{\text {inclusion }}=.600 ;$ awareness and cue validity, $F(1,18)=.412$, $p=.529, \mathrm{n}_{\mathrm{p}}{ }^{2}=.022, \mathrm{BF}_{\text {inclusion }}=.974$. Finally, the three-way interaction between awareness, cue type, and cue validity did not reach significance, $F(1,18)=.127, p=.726, \eta_{\mathrm{p}}{ }^{2}=.007$, $\mathrm{BF}_{\text {inclusion }}=.334$, suggesting that the same-location benefit for target-colored cues and the same-location cost for distractorcolored cues were not differentially affected by awareness. Thus, as in the previous two experiments, we found behavioral evidence for feature-based cueing effects and distractor costs even when the evoking events were not consciously perceived.

We ran an analogous ANOVA on error rates (see Table 4). There were no significant main effects of awareness, $F(1,18)$ $=.134, p=.719, \mathrm{\eta}_{\mathrm{p}}{ }^{2}=.007, \mathrm{BF}_{10}=.194$; cue type, $F(1,18)=$ $1.426, p=.248, \mathrm{\eta}_{\mathrm{p}}{ }^{2}=.073, \mathrm{BF}_{10}=.321$; or cue validity, $F(1$, $18)=.279, p=.604, \mathrm{\eta}_{\mathrm{p}}{ }^{2}=.015, \mathrm{BF}_{10}=.209$. There was,

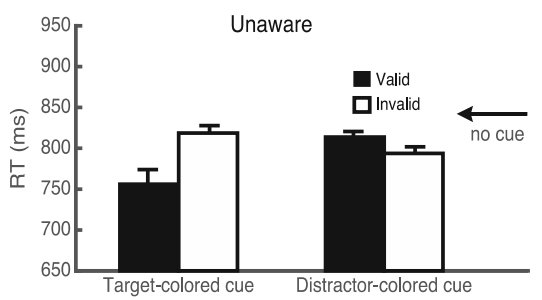

included trials in which participants reported having some awareness of the cue. By contrast, the unaware condition included only those trials in which participants indicated they were not aware of the cue. The small arrow on the right indicates the mean reaction time for the no-cue condition. Error bars represent within-subjects standard errors of the means 
Table 4 Mean reaction times and error rates for the different cue color and awareness conditions of Experiment 3

\begin{tabular}{|c|c|c|c|c|c|c|c|c|}
\hline \multirow[t]{3}{*}{ Cue validity } & \multicolumn{4}{|c|}{ Target-colored cue } & \multicolumn{4}{|c|}{ Distractor-colored cue } \\
\hline & \multicolumn{2}{|l|}{ Unaware } & \multicolumn{2}{|l|}{ Aware } & \multicolumn{2}{|l|}{ Unaware } & \multicolumn{2}{|l|}{ Aware } \\
\hline & RT (ms) & Error rate $(\%)$ & $\mathrm{RT}(\mathrm{ms})$ & Error rate $(\%)$ & $\mathrm{RT}(\mathrm{ms})$ & Error rate $(\%)$ & $\mathrm{RT}(\mathrm{ms})$ & Error rate $(\%)$ \\
\hline Valid & $756(34)$ & $7.3(7)$ & $830(26)$ & $9.4(8.2)$ & $814(26)$ & $9.2(6.7)$ & $867(25)$ & $8.9(9.1)$ \\
\hline Invalid & 819 (29) & $10.8(11.5)$ & 881 (29) & $9.9(8.5)$ & 794 (28) & $7.8(6.2)$ & 841 (27) & $8.2(8.3)$ \\
\hline
\end{tabular}

Note. Standard errors are given in parentheses

however, a significant interaction between cue type and cue validity, $F(1,18)=8.042, p=.011, \mathrm{\eta}_{\mathrm{p}}^{2}=.309, \mathrm{BF}_{\text {inclusion }}=$ .300. Follow-up pairwise $t$ tests revealed that this two-way interaction was because there were more errors when invalid cues were target colored $(M=.104, S D=.099)$ than when they were distractor colored $(M=.080, S D=.070)$, but this difference did not survive Bonferroni correction with an alpha level of $.0125, t(18)=-2.322, p=.032, d=-.533, \mathrm{BF}_{10}=2.006$. None of the other interactions were significant (Awareness $\times$ Cue Type, $F(1,18)=.148, p=.705, \eta_{\mathrm{p}}^{2}=.008, \mathrm{BF}_{\text {inclusion }}=$ .028 ; Awareness $\times$ Cue Validity, $F(1,18)=.912, p=.352, \eta_{\mathrm{p}}^{2}$ $=.048, \mathrm{BF}_{\text {inclusion }}=.026$; Awareness $\times$ Cue Type $\times$ Cue Validity, $F(1,18)=2.229, p=.153, \eta_{\mathrm{p}}^{2}=.110, \mathrm{BF}_{\text {inclusion }}=$ .008 .

\section{ERP analysis}

The ERP data were analyzed as a function of cue awareness (aware or unaware), electrode laterality (contralateral or ipsilateral to the cue location), and cue condition (target-colored cue or distractor-colored cue). As seen in Fig. 7, starting approximately $200 \mathrm{~ms}$ after cue onset, a negative component $\left(\mathrm{N}_{\mathrm{T}}\right)$ was evident for all conditions, but with a slightly larger negative amplitude for the target-colored cue trials than the distractor-colored cue trials. Interestingly, starting approximately $350 \mathrm{~ms}$ after cue onset, a positive component $\left(\mathrm{P}_{\mathrm{D}}\right)$ was also evident for distractor-colored cue trials, but not for target-colored cue trials. To capture the sequence of these laterality effects, we analyzed mean ERP amplitudes during two time windows: An earlier time window focused on the $\mathrm{N}_{T}$ component (200 to $300 \mathrm{~ms}$ after cue onset, to match the cuerelated time window analyzed in Experiment 2), and a later time window focused on the $\mathrm{P}_{\mathrm{D}}$ component (350 to $500 \mathrm{~ms}$ after cue onset). Past research has shown that the $\mathrm{P}_{\mathrm{D}}$ component can vary over a broad time range that depends on the evoking stimulus and experimental task (e.g., Burra \& Kerzel, 2014; Cosman et al., 2018; Gaspar \& McDonald, 2014; Gaspelin \& Luck, 2018a; Hickey et al., 2009; Hilimire et al., 2011; Sawaki, Geng, \& Luck, 2012; Sawaki $\&$ Luck, 2010). To be sure any $\mathrm{P}_{\mathrm{D}}$ effect was not cancelled out by the opposite polarity of the $\mathrm{N}_{\mathrm{T}}$ component, we chose a time window that was outside the $\mathrm{N}_{\mathrm{T}}$ time window. Note also that the cue-related ERP responses were always collapsed across valid and invalid trials (with respect to subsequent target location), so any evoked activity arising from the subsequent onset of target events was effectively cancelled out.

ERP data for the $\mathrm{N}_{\mathrm{T}}$ and $\mathrm{P}_{\mathrm{D}}$ responses were submitted to separate 2 (awareness) $\times 2$ (electrode laterality) $\times 2$ (cue condition) repeated-measures ANOVAs on the mean amplitude for each participant during each time window.

$\mathrm{N}_{\mathrm{T}}$ component There was no significant main effect of awareness on cue-evoked ERPs during the earlier time window, $F(1$, 18) $=.011, p=.918, \mathrm{n}_{\mathrm{p}}^{2}=.001, \mathrm{BF}_{10}=.175$. Responses did not differ between aware trials $(M=-.090, S D=.931)$ and unaware trials $(M=-.104, S D=.664)$. There was a significant main effect of electrode laterality, $F(1,18)=18.402, p=.000441, \mathrm{\eta}_{\mathrm{p}}{ }^{2}=.506$, $\mathrm{BF}_{10}=1.254 \mathrm{e}+6$. Responses at electrode sites contralateral to the cue were more negative $(M=-.439, S D=.942)$ than responses at electrode sites ipsilateral to the cue $(M=.246, S D=.703)$. There was also a significant effect of cue condition, $F(1,18)=5.096, p$ $=.037, \mathrm{n}_{\mathrm{p}}^{2}=.221, \mathrm{BF}_{10}=1.762$. Overall responses for targetcolored cue trials were more negative $(M=-.236, S D=.854)$ than those for distractor colored-cue trials $(M=.043, S D=.745)$. There was no significant interaction between cue condition and electrode laterality, $F(1,18)=2.739, p=.115, \eta_{\mathrm{p}}^{2}=.132$, $\mathrm{BF}_{\text {inclusion }}=.861$, between cue condition and awareness, $F(1$, 18) $=1.247, p=.279, \mathrm{\eta}_{\mathrm{p}}^{2}=.065, \mathrm{BF}_{\text {inclusion }}=.112$, or between awareness and cue laterality, $F(1,18)=1.420, p=.249, \mathrm{\eta}_{\mathrm{p}}^{2}$ $=.073, \mathrm{BF}_{\text {inclusion }}=.146$. There was, however, a significant three-way interaction between cue condition, awareness, and electrode laterality, $F(1,18)=9.639, p=.006, \mathrm{\eta}_{\mathrm{p}}{ }^{2}=.349$, $\mathrm{BF}_{\text {inclusion }}=.050$. To investigate this three-way interaction, we analyzed the interaction between cue condition and cue laterality at each awareness level.

For aware trials, there was no significant effect of cue condition, $F(1,18)=1.854, p=.190, \mathrm{\eta}_{\mathrm{p}}^{2}=.093, \mathrm{BF}_{10}=.359$. There was, however, a significant effect of cue laterality, $F(1$, 18) $=13.943, p=.002, \eta_{\mathrm{p}}{ }^{2}=.436, \mathrm{BF}_{10}=2,443.150$, as well as a significant interaction between cue condition and cue laterality, $F(1,18)=9.643, p=.006, \mathrm{\eta}_{\mathrm{p}}^{2}=.349, \mathrm{BF}_{\text {inclusion }}=$ 1.231. To investigate whether there was an $\mathrm{N}_{\mathrm{T}}$ to both targetcolored and distractor-colored cues for aware trials, we followed up this interaction with pairwise $t$ tests. On target- 
a
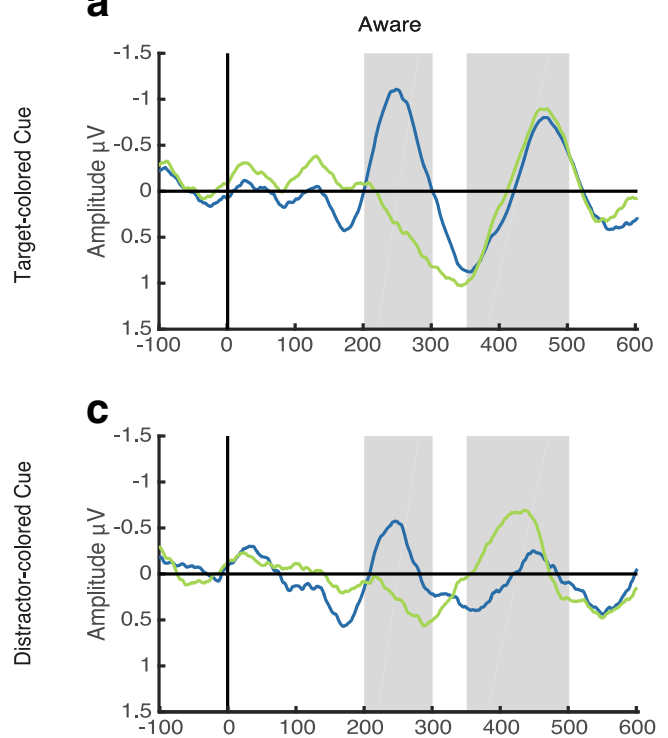

Fig. 7 Grand average event-related potentials (ERPs) in response to cue events, averaged across posterior electrode sites (P7/P8, P9/P10, PO7/ PO8) contralateral to the cue location (blue) and ipsilateral to the cue location (green). The ERPs are shown as a function of awareness (aware vs. unaware) and cue condition (target-colored cue vs. distractor-colored cue). a Average ERPs when a target-colored cue was presented and participants were aware of the cue. b Average ERPs when a target-colored cue was presented and participants were unaware of the cue. c Average

colored cue trials, mean ERPs were significantly more negative at electrode sites contralateral to the cue location $(M=$ $-.720, S D=1.445)$ than at electrode sites ipsilateral to the cue location $(M=.349, S D=.962), t(18)=-3.950, p=.000939, d$ $=-.906, \mathrm{BF}_{10}=39.032$. This pattern was also found for distractor-colored cue trials, such that ERPs were significantly more negative at electrode sites contralateral to the cue location $(M=-.255, S D=1.054)$ than at electrode sites ipsilateral to the cue location $(M=.267, S D=.850), t(18)=-2.872, p=$ $.010, d=-.659, \mathrm{BF}_{10}=5.145$. We performed permutation tests, which verified these results (see the Supplemental Material).

To determine whether the magnitude of the $\mathrm{N}_{T}$ response differed between target-colored and distractorcolored cues for aware trials, we computed a difference score by subtracting responses at ipsilateral electrode sites from responses at contralateral sites, separately for targetcolored and distractor-colored cue trials. The magnitude of this difference (i.e., the size of the $\mathrm{N}_{\mathrm{T}}$ ) was greater for target-colored cues (mean difference $=-1.069, S D=$ 1.180) than for distractor-colored cues (mean difference $=$ -.522, $S D=.792), t(19)=-3.105, p=.006, d=-.712$, $\mathrm{BF}_{10}=7.859$. Thus, there was a significant $\mathrm{N}_{\mathrm{T}}$ to both target-colored and distractor-colored cues in aware trials, but the magnitude of the response was larger for targetcolored cues. There was no evidence of a $\mathrm{P}_{\mathrm{D}}$ component during this earlier time window. b
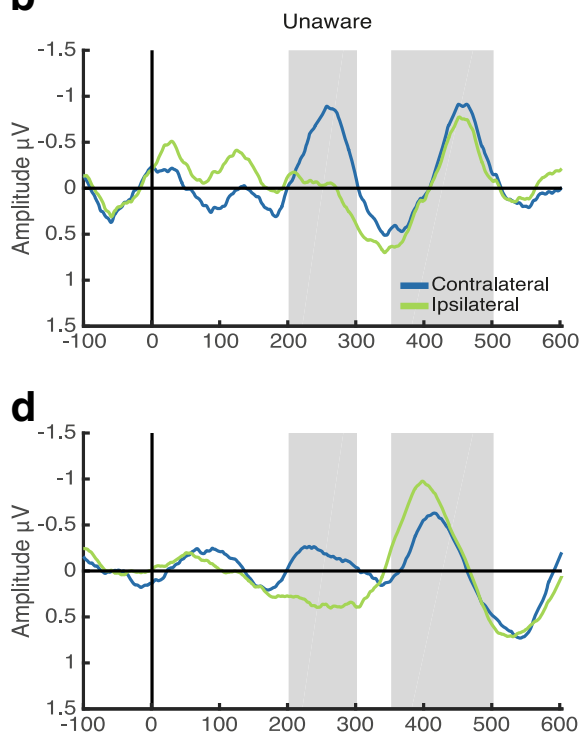

ERPs when a distractor-colored cue was presented and participants were aware of the cue. d Average ERPs when a distractor-colored cue was presented and participants were unaware of the cue. Cue onset is at time zero. Shaded areas represent analyzed time windows for the cue-related response (200-300 ms after cue onset and 350-500 ms). Data have been smoothed using a sliding boxcar for display only. All analyses were performed on the unsmoothed data. (Color figure online)

For the unaware trials, there was a significant effect of cue condition, $F(1,18)=5.775, p=.027, \mathrm{\eta}_{\mathrm{p}}^{2}=.243, \mathrm{BF}_{10}=$ 2.386. There was also a significant effect of cue laterality, $F(1,18)=14.493, p=.001, \eta_{\mathrm{p}}{ }^{2}=.446, \mathrm{BF}_{10}=118.123$, but there was no significant interaction between cue condition and cue laterality, $F(1,18)=.062, p=.807, \eta_{\mathrm{p}}{ }^{2}=.003, \mathrm{BF}_{\text {inclusion }}$ $=1.030$. Pairwise $t$ tests showed that on target-colored cue trials, mean ERPs were significantly more negative at electrode sites contralateral to the cue location $(M=-.588, S D=$ 1.086) than at electrodes ipsilateral to the cue location $(M=$ $.014, S D=.712), t(18)=-2.597, p=.018, d=-.596, \mathrm{BF}_{10}=$ 3.171. This pattern was also found for distractor-colored cues in unaware trials, such that mean ERPs were significantly more negative at electrode sites contralateral to the cue location $(M=-.194, S D=.709)$ than at electrodes ipsilateral to the cue location $(M=.354, S D=.822), t(18)=-4.379, p=$ $.000362, d=-1.005, \mathrm{BF}_{10}=89.846$. Thus, there was a significant $\mathrm{N}_{\mathrm{T}}$ to both target-colored and distractor-colored cues, but this did not differ between the two cue conditions. Once again there was no evidence of a $P_{D}$ component during this earlier time window.

$P_{D}$ component There was no significant effect of awareness on cue-evoked ERPs during the later time window (350 to $500 \mathrm{~ms}$ after cue onset), $F(1,18)=.763, p=.394, \mathrm{\eta}_{\mathrm{p}}{ }^{2}=$ $.041, \mathrm{BF}_{10}=.298$. Responses did not differ between aware trials $(M=-.114, S D=.821)$ and unaware trials $(M=-.232$, 
$S D=.902$ ). In addition, there was no significant main effect of electrode laterality, $F(1,18)=3.653, p=.072, \mathrm{\eta}_{\mathrm{p}}{ }^{2}=.169$, $\mathrm{BF}_{10}=.396$. Responses did not differ between electrode sites contralateral to the cue $(M=-.099, S D=.817)$ and those at electrodes ipsilateral to the cue $(M=.246, S D=.838)$. Finally, there was no significant effect of cue condition, $F(1,18)=$ $.057, p=.815, \mathrm{\eta}_{\mathrm{p}}{ }^{2}=.003, \mathrm{BF}_{10}=.186$. Overall responses for target-colored-cue trials $(M=-.150, S D=-.682)$ did not differ from those for distractor-colored-cue trials $(M=$ $-.196, S D=1.091)$. There was, however, a significant interaction between cue condition and electrode laterality, $F(1,18)$ $=6.002, p=.025, \mathrm{\eta}_{\mathrm{p}}{ }^{2}=.250, \mathrm{BF}_{\text {inclusion }}=.562$. To investigate whether there was a $\mathrm{P}_{\mathrm{D}}$ to both target-colored and distractorcolored cues, we followed up this interaction with pairwise $t$ tests (collapsed across the awareness condition). In targetcolored-cue trials, mean ERPs did not differ between electrode sites contralateral to the cue location $(M=-.151, S D=.720)$ and electrode sites ipsilateral to the cue location $(M=-.150$, $S D=.730), t(19)=-.013, p=.990, d=-.003, \mathrm{BF}_{10}=.238 . \mathrm{In}$ contrast, in distracter-colored-cue trials, ERPs were significantly more positive at electrode sites contralateral to the cue location $(M=-.048, S D=1.133)$ than at electrode sites ipsilateral to the cue location $(M=-.343, S D=1.077), t(19)=$ 3.693, $p=.002, d=.847, \mathrm{BF}_{10}=23.795$. Thus, there was a significant $\mathrm{P}_{\mathrm{D}}$ for distractor-colored cues, but not for targetcolored cues. None of the other interaction terms approached significance (Cue Condition $\times$ Awareness), $F(1,18)=.288, p$ $=.598, \mathrm{\eta}_{\mathrm{p}}{ }^{2}=.016, \mathrm{BF}_{\text {inclusion }}=.026$; Awareness $\times$ Electrode Laterality, $F(1,18)=2.204, p=.155, \mathrm{\eta}_{\mathrm{p}}{ }^{2}=.109, \mathrm{BF}_{\text {inclusion }}=$ .049; Cue Condition $\times$ Awareness $\times$ Electrode Laterality, $F(1$, $18)=.149, p=.704, \mathrm{\eta}_{\mathrm{p}}{ }^{2}=.008, \mathrm{BF}_{\text {inclusion }}=.003$. We performed permutation tests, which verified these results (see the Supplemental Material).

\section{Discussion}

In line with the findings of Experiments 1 and 2, we found an RT benefit for valid versus invalid target-colored cues, with no difference in magnitude between cue-aware and cue-unaware trials. Target-colored cues and distractor-colored cues elicited an $\mathrm{N}_{\mathrm{T}}$ response for both cue-aware and cue-unaware trials. In line with our findings from Experiment 2, the magnitude of the $\mathrm{N}_{\mathrm{T}}$ response to target-colored cues was reliably larger for cue-aware trials than for cue-unaware trials. We also found that distractor-colored cues elicited an equivalent $\mathrm{P}_{\mathrm{D}}$ response for both cue-aware and cue-unaware trials, whereas targetcolored cues did not elicit a reliable $\mathrm{P}_{\mathrm{D}}$. Thus, at the neural level, target processing is modulated by awareness, but distractor processing is not. Taken together, the results of Experiment 3 suggest that top-down task goals can elicit selective enhancement of task-relevant features (as measured by the $\mathrm{N}_{\mathrm{T}}$ ) and active suppression of task-irrelevant features (as measured by the $\mathrm{P}_{\mathrm{D}}$ ), even in the absence of cue awareness.
Interestingly, enhancement occurred earlier (200-300 ms after cue onset) than suppression of task-relevant features (350$500 \mathrm{~ms}$ after cue onset), suggesting that the N2pc results reported in Experiment 2 are not likely to reflect a combined $N_{T}$ and $\mathrm{P}_{\mathrm{D}}$ response.

\section{General discussion}

A key debate in the visual attention literature concerns how attention and perceptual awareness are related. Some researchers propose that attention and consciousness are intimately linked (Chun \& Wolfe, 2000; Cohen et al., 2012; De Brigard, \& Prinz, 2010; Mack \& Rock, 1998; Merikle \& Joordens, 1997; Mole, 2008; O’Regan \& Noe, 2001; Posner, 1994; Prinz, 2011; Velmans, 1996), whereas others suggest that the two processes can act independently (Baars, 1997, 2005; Bachmann, 2006; Block, 2005; Dehaene et al., 2006; Iwasaki, 1993; Kentridge, Heywood, \& Weiskrantz, 1999b; Kentridge et al., 2004; Koch, 2004; Koch \& Tsuchiya, 2007; Lamme, 2003; Maier et al., 2008; Naccache et al., 2002; van Boxtel et al., 2010; Watanabe et al., 2011; Woodman \& Luck, 2003). Here, we investigated the independent effects of spatial attention and perceptual awareness on feature-based cueing effects. Specifically, we were interested in whether the relationship between attention and perceptual awareness was consistent across behavioral and neural signatures of feature-based cueing effects. Previous research has shown that behavioral measures of feature-based cueing effects are independent of perceptual awareness (e.g., Ansorge \& Neumann, 2005; Hsieh et al., 2011; Ivanoff \& Klein, 2003; Lamy et al., 2015), but there has been little work on the effects of attention and perceptual awareness on neural measures of feature-based cueing effects.

In Experiment 1, we ran a direct replication of Lamy et al. (2015, Experiment 1), in which participants searched for a colordefined target that was preceded by a cue that was masked via CFS. Like Lamy et al. (2015), we found an RT benefit for valid target-colored cues, the magnitude of which did not differ between aware and unaware cues. We also found an RT cost for distractor-colored cues, which did not differ with cue awareness. This latter finding is in contrast to that of Lamy et al. (2015), who found an RT cost for distractor-colored cues on aware trials but not on unaware trials. Our findings suggest that when measured behaviorally, attentional mechanisms of selective enhancement and active suppression appear to act independently from perceptual awareness. Importantly, we replicated these behavioral results across all three experiments.

In Experiment 2, we presented a pair of colored cues, one in each visual hemifield, and found that target-colored cues evoked an N2pc response for both consciously perceived and unperceived cues. The magnitude of this N2pc response was larger for aware cues than for unaware ones. The N2pc is widely assumed to index attentional orienting to a specific location in 
space (Heinze et al., 1990; Luck, 2005; Luck \& Hillyard, 1994; but other processes have also been implicated; see Naughtin, Mattingley, \& Dux, 2016). Since both aware and unaware cues in our study produced a significant N2pc response, it seems reasonable to conclude that selective attention is required to resolve competition between goal-relevant and distractor stimuli even when those stimuli are not consciously perceived.

In Experiment 3, we presented just one cue (either target colored or distractor colored) within each cue display, and measured $\mathrm{N}_{\mathrm{T}}$ and $\mathrm{P}_{\mathrm{D}}$ responses to the cue stimuli. We found an $\mathrm{N}_{\mathrm{T}}$ to target-colored and distractor-colored cues when observers were both aware and unaware of those cues. In line with predictions, the magnitude of the $\mathrm{N}_{\mathrm{T}}$ response was larger for aware target-colored cues than for unaware target-colored cues. Interestingly, we also found an $\mathrm{N}_{\mathrm{T}}$ to distractor-colored cues, the magnitude of which did not differ between aware and unaware trials. Previous research has found that the $\mathrm{N} 2 \mathrm{pc} / \mathrm{N}_{\mathrm{T}}$ response is evoked when stimuli are goal relevant, but not when stimuli are task irrelevant (Eimer \& Kiss, 2008; Eimer et al., 2009; Kiss et al., 2008; Lien et al., 2008). Thus, our finding of an $\mathrm{N}_{\mathrm{T}}$ response to distractor-colored cues might seem unexpected. However, one important component of our design is that we asked participants to report their awareness of the cue on every trial. Thus, all cues, both target colored and distractor colored, were relevant to the awareness task in our experiments. Previous research has shown that cues that have some taskrelevant features produce an N2pc response, even when those cues do not share all task-relevant features (Kiss, Grubert, \& Eimer, 2013). Given that an $\mathrm{N}_{\mathrm{T}}$ is typically not found for distractor-colored cues in feature-based cueing studies, our finding of an $\mathrm{N}_{\mathrm{T}}$ response to distractor-colored cues highlights how different this version of the paradigm is from the original paradigm introduced by Folk et al. (1992). The presence of the $\mathrm{N}_{\mathrm{T}}$ response to distractor-colored cues suggests that attention was directed to the location of the distractor-colored cue. This finding might seem contradictory to our observation of a samelocation RT cost for distractor-colored cues. We suspect that the $\mathrm{N}_{\mathrm{T}}$ response reflects an early stage of processing, whereas the RT measure captures a later stage in the stimulus-response chain (as we discuss in detail below).

In Experiment 3, we also observed a $\mathrm{P}_{\mathrm{D}}$ response to distractor-colored cues that occurred later in time than the $\mathrm{N}_{T}$ response. The magnitude of the $\mathrm{P}_{\mathrm{D}}$ response did not differ between aware and unaware cues. Importantly, we found no evidence of a $P_{D}$ response to target-colored cues. The timing of the $\mathrm{P}_{\mathrm{D}}$ in our study was somewhat later than has been observed previously (Burra \& Kerzel, 2014; Gaspar \& McDonald, 2014; Gaspelin \& Luck, 2018a; Hickey et al., 2009; Hilimire et al., 2011; Sawaki et al., 2012; Sawaki \& Luck, 2010). According to the signal suppression hypothesis (Sawaki \& Luck, 2010), top-down suppression is typically initiated even before a stimulus is presented. Thus, once participants are informed of their task goal (e.g., "Find the red T shape and ignore the green T shape"), top-down signals act to enhance firing rates of neurons involved in processing goalrelevant features (e.g., red), and to attenuate the firing of neurons involved in processing goal-irrelevant features (e.g., green; e.g., Maunsell \& Cook, 2002). When a target-colored cue is then presented, neurons involved in processing critical stimulus features are more likely to fire and neurons involved in processing goal-irrelevant stimuli are less likely to fire (Hamker, 2005; Treue \& Martínez-Trujillo, 1999). As all cues were relevant to the awareness task in our experiments, however, active suppression was not required until after cue onset. Thus, it is possible that cues were initially enhanced in order to perform the cue awareness task, but then were quickly suppressed for target processing and rapid response.

\section{Relationship between attention and perceptual awareness}

Lamy et al. (2015) found an RT benefit for target-colored cues that was independent of perceptual awareness, and an RT cost for distractor-colored cues that depended on perceptual awareness. Across the three experiments presented here, we failed to replicate the independent effects of perceptual awareness on RT costs. Given that we used the same methodological design as Lamy et al., this finding is surprising. We note that the RT cost for unaware cues is quite small in numerical terms (mean cost of $23 \mathrm{~ms}$ across the three experiments). As we used a larger sample and had observers perform more trials than did Lamy et al. (2015), we may have simply had more statistical power to find this small effect. Interestingly, a recent paper by Schoeberl et al. (2018) also found that the same location cost was independent of cue awareness. Thus, converging evidence suggests that, when measured behaviorally, the attentional mechanisms of selective enhancement and active suppression both appear to be independent of awareness.

Interestingly, our neural data provide a different story as to the relationship between attention and perceptual awareness. We found that the neural responses associated with enhancement (the $\mathrm{N} 2 \mathrm{pc} / \mathrm{N}_{\mathrm{T}}$; Hickey et al., 2009) were dependent on awareness, whereas the neural response associated with suppression (the $\mathrm{P}_{\mathrm{D}}$; Hickey et al., 2009) was independent of awareness. Thus, our findings suggest that while the neural signatures of top-down enhancement of sensory processes are modulated by awareness, the neural signatures of top-down suppression are not.

Overall our findings have two important implications for understanding the relationship between attention and perceptual awareness. The first is that conclusions about the manner in which attention and awareness relate are likely contingent on how any effects on behavior and brain activity are measured. The variance in neural responses and the variance in RT measures might be assumed to arise from a common source. Thus, it might be expected that the pattern of ERP responses would 
match those of the behavioral responses (i.e., RTs). The N2pc/ $\mathrm{N}_{\mathrm{T}}$ component, however, represents an early stage in the stimulusresponse chain, whereas RTs represent the final outcome of that chain (or conceivably one of many consequences of stimulus processing). It is possible, therefore, that $\mathrm{N} 2 \mathrm{pc} / \mathrm{N}_{\mathrm{T}}$ amplitude is determined by one stage of processing, whereas the RT effect is determined by later processing stages involved in decision-making, response selection, and/or execution. Our findings suggest that these later stimulus-processing stages are largely independent of the magnitude of responses during the early processing of visual features.

The second implication of our work is that the mechanisms of selective attention are likely the combination of (at least) two processes-selective enhancement and active suppression - and these processes seem to relate in different ways to perceptual awareness. While the neural measures of selective enhancement appear to depend on awareness, the neural measures of active suppression do not.

To claim that perceptual awareness is entirely independent of attention, it must be shown that all forms of attentional bias involved in all stages of processing are independent of whether a stimulus will be consciously perceived. Our findings suggest that the relationship between attention and perceptual awareness is a complex one that depends on the type of processing involved in any given task. Future research on the relationship between attention and perceptual awareness should focus on how these different mechanisms interact at different stages of the information processing hierarchy.

Acknowledgements S.L.T. was supported by an Australian Government Research Training Program Scholarship and the Queensland Brain Institute Top-Up Scholarship. P.E.D. was supported by an Australian Research Council (ARC) Future Fellowship (FT120100033). J.B.M. was supported by an ARC Australian Laureate Fellowship (FL110100103) and the ARC Centre of Excellence for Integrative Brain Function (ARC Centre Grant CE140100007).

Publisher's note Springer Nature remains neutral with regard to jurisdictional claims in published maps and institutional affiliations.

\section{References}

Andersen, S. K., \& Muller, M. M. (2010). Behavioral performance follows the time course of neural facilitation and suppression during cued shifts of feature-selective attention. Proceedings of the National Academy of Sciences of the United States of America, 107, 13878-13882.

Anderson, B. A., \& Folk, C. L. (2012). Dissociating location-specific inhibition and attention shifts: Evidence against the disengagement account of contingent capture. Attention, Perception, \& Psychophysics 74(6), 1183-1198. https://doi.org/10.3758/s13414012-0325-9

Ansorge, U., \& Neumann, O. (2005). Intentions determine the effect of invisible metacontrast-masked primes: Evidence for top-down contingencies in a peripheral cuing task. Journal of Experimental Psychology: Human Perception and Performance, 31, 762-777. https://doi.org/10.1037/0096-1523.31.4.762

Ansorge, U., Horstmann, G., \& Worschech, F. (2010). Attentional capture by masked colour singletons. Vision Research, 50(19), 2015-2027. https://doi.org/10.1016/j.visres.2010.07.015

Ansorge, U., Kiss, M., \& Eimer, M. (2009). Goal-driven attentional capture by invisible colors: Evidence from event-related potentials. Psychonomic Bulletin \& Review, 16(4), 648-653. https://doi.org/ 10.3758/pbr.16.4.648

Baars, B. J. (1997). In the theatre of consciousness: Global workspace theory, a rigorous scientific theory of consciousness. Journal of Consciousness Studies 4, 292-309.

Baars, B. (2005). Global workspace theory of consciousness: Towards a cognitive neuroscience of human experience? Progress in Brain Research, 150, 45-53.

Bachmann, T. (2006). A single metatheoretical framework for a number of conscious vision phenomena. In Q. Jing (Ed.), Psychological science around the world (pp. 229-242). London, UK: Psychology Press.

Belopolsky, A. V., Schreij, D., \& Theeuwes, J. (2010). What is top-down about contingent capture? Attention, Perception, \& Psychophysics, 72, 326-341. https://doi.org/10.3758/APP.72.2.326

Bisley, J. W., \& Goldberg, M. E. (2010). Attention, intention, and priority in the parietal lobe. Annual Review of Neuroscience, 33, 1-21.

Block, N. (2005). Two neural correlates of consciousness. Trends in Cognitive Sciences, 9, 46-52.

Braithwaite, J. J., \& Humphreys, G. W. (2003). Inhibition and anticipation in visual search: Evidence from effects of color foreknowledge on preview search. Perception \& Psychophysics, 65, 213-237.

Burra, N., \& Kerzel, D. (2014). The distractor positivity (Pd) signals lowering of attentional priority: Evidence from event-related potentials and individual differences. Psychophysiology, 51(7), 685-696.

Carmel, T., \& Lamy, D. (2014). The same-location cost is unrelated to attentional settings: An object-updating account. Journal of Experimental Psychology: Human Perception and Performance, 40, 1465-1478. https://doi.org/10.1037/a0036383

Chelazzi, L., Miller, E. K., Duncan, J., \& Desimone, R. (1993). A neural basis for visual search in inferior temporal cortex. Nature, 363,345 347.

Chica, A. B., \& Bartolomeo, P. (2012). Attentional routes to conscious perception. Frontiers in Psychology, 3,1. https://doi.org/10.3389/ fpsyg.2012.00001

Chun, M. M., \& Wolfe, J. M. (2000). Visual attention. In E. B. Goldstein (Ed.). Blackwell's handbook of perception (pp. 272-310). Oxford, UK: Blackwell.

Cohen, M. A., Cavanagh, P., Chun, M. M., \& Nakayama, K. (2012). The attentional requirements of consciousness. Trends in Cognitive Sciences, 16, 411-417.

Corbetta, M., Miezin, F. M., Dobmeyer, S., Shulman, G. L., \& Petersen, S. E. (1990). Attentional modulation of neural processing of shape, color, and velocity in humans. Science, 248, 1556-1559.

Corbetta, M., \& Shulman, G. L. (2002). Control of goal-directed and stimulus-driven attention in the brain. Nature Reviews Neuroscience, 3, 201-215. https://doi.org/10.1038/nrn755

Cosman, J. D., Lowe, K. A., Woodman, G. F., \& Schall, J. D. (2018). Prefrontal control of visual distraction. Current Biology, 28, 1-7.

De Brigard, F., \& Prinz, J. (2010). Attention and consciousness. Wiley Interdisciplinary Reviews: Cognitive Science, 1, 51-59.

Dehaene, S., Changeux, J., Naccache, L., Sackur, J., \& Sergent, C. (2006). Conscious, preconscious, and subliminal processing: A testable taxonomy. Trends in Cognitive Sciences, 10, 204-211.

Delorme, A., \& Makeig, S. (2004). Eeglab: An open source toolbox for analysis of single-trial EEG dynamics including independent component analysis. Journal of Neuroscience Methods, 134, 9-21. 
Desimone, R., \& Duncan, J. (1995). Neural mechanisms of selective visual attention. Annual Review of Neuroscience, 18, 193-222. https://doi.org/10.1146/annurev.neuro.18.1.193

Eimer, M. (1996). The N2pc component as an indicator of attentional selectivity. Electroencephalography and Clinical Neurophysiology, 99(3), 225-234. https://doi.org/10.1016/s0921-884x(96)95711-2

Eimer, M., \& Kiss, M. (2008). Involuntary attentional capture is determined by task set: Evidence from event-related brain potentials. Journal of Cognitive Neuroscience, 20, 1423-1433.

Eimer, M., Kiss, M., Press, C., \& Sauter, D. (2009). The roles of featurespecific task set and bottom-up salience in attentional capture: An ERP study. Journal of Experimental Psychology: Human Perception and Performance, 35, 1316-1328. https://doi.org/10. 1037/a0015872

Folk, C. L., \& Remington, R. W. (1999). Can new objects override attentional control settings? Perception \& Psychophysics, 61, 727-739. https://doi.org/10.1037/e536982012-031

Folk, C. L., \& Remington, R. W. (2008). Bottom-up priming of top-down attentional control settings. Visual Cognition, 16, 215-231. https:// doi.org/10.1080/13506280701458804

Folk, C. L., Remington, R. W., \& Johnston, J. C. (1992). Involuntary covert orienting is contingent on attentional control settings. Journal of Experimental Psychology: Human Perception and Performance, 18(4), 1030-1044. https://doi.org/10.1037/00961523.18.4.1030

Folk, C. L., Remington, R. W., \& Wright, J. H. (1994). The structure of attentional control: Contingent attentional capture by apparent motion, abrupt onset, and color. Journal of Experimental Psychology: Human Perception and Performance, 20, 317-329. https://doi.org/ 10.1037/0096-1523.20.2.317

Fries, P., Reynolds, J. H., Rorie, A. E., \& Desimone, R. (2001). Modulation of oscillatory neuronal synchronization by selective visual attention. Science, 291, 1560-1563.

Gaspar, J. M., \& McDonald, J. J. (2014). Suppression of salient objects prevents distraction in visual search. The Journal of Neuroscience, 34(16), 5658-5666.

Gaspelin, N., \& Luck, S. (2018a). The role of inhibition in avoiding distraction by salient stimuli. Trends in Cognitive Sciences, 22, 79-92.

Gaspelin, N., \& Luck, S. J. (2018b). Electrophysiological and behavioral evidence of suppression of salient-but-irrelevant stimuli. Journal of Cognitive Neuroscience, 30(9), 1265-1280.

Gibson, B. S., \& Amelio, J. (2000). Inhibition of return and attentional control settings. Perception \& Psychophysics, 62, 496-504. https:// doi.org/10.3758/bf03212101

Gibson, B. S., \& Kelsey, E. M. (1998). Stimulus-driven attentional capture is contingent on attentional set for displaywide visual features. Journal of Experimental Psychology: Human Perception and Performance, 24, 699-706. https://doi.org/10.1037/0096-1523.24. 3.699

Gruber, T., Muller, M. M., Keil, A., \& Elbert, T. (1999). Selective visualspatial attention alters induced gamma band responses in the human EEG. Clinical Neurophysiology, 110, 2074-2085.

Hamker, F. H. (2005). The reentry hypothesis: The putative interaction of the frontal eye field, ventrolateral prefrontal cortex, and areas V4, IT for attention and eye movement. Cerebral Cortex, 15, 431-447. https://doi.org/10.1093/cercor/bhh146

Heinze, H. J., Luck, S. J., Mangun, G. R., \& Hillyard, S. A. (1990). Visual event-related potentials index focused attention within bilateral stimulus arrays. I. Evidence for early selection. Electroencephalography and Clinical Neurophysiology, 75(6), 511-527. https://doi.org/10. 1016/0013-4694(90)90138-a

Hickey, C., Di Lollo, V., \& McDonald, J. J. (2009). Electrophysiological indices of target and distractor processing in visual search. Journal of Cognitive Neuroscience, 21(4), 760-775. https://doi.org/10.1162/ jocn.2009.21039
Hilimire, M. R., Mounts, J. R., Parks, N. A., \& Corballis, P. M. (2011). Dynamics of target and distractor processing in visual search: Evidence from event-related brain potentials. Neuroscience Letters, 495, 196-200.

Hillyard, S. A., \& Anllovento, L. (1998). Event-related brain potentials in the study of visual selective attention. Proceedings of the National Academy of Sciences of the United States of America, 95, 781-787.

Hopf, J. M., Boehler, C. N., Luck, S. J., Tsotsos, J. K., Heinze, H. J., \& Schoenfeld, M. A. (2006a). Direct neurophysiological evidence for spatial suppression surrounding the focus of attention in vision. Proceedings of the National Academy of Sciences of the United States of America, 103, 1053-1058.

Hopf, J. M., Luck, S. J., Boelmans, M. A., Schoenfeld, M. A., Boehler, C. N., Rieger, J., \& Heinze, H. J. (2006b). The neural site of attention matches the spatial scale of perception. The Journal of Neuroscience, 26, 3532-3540

Hsieh, P. J., Colas, J. T., \& Kanwisher, N. (2011). Pop-out without awareness: Unseen feature singletons capture attention only when topdown attention is available. Psychological Science, 22, 1220 1226. https://doi.org/10.1177/0956797611419302

Itti, L., \& Koch, C. (2001). Computational modelling of visual attention. Nature Reviews Neuroscience, 2(3), 194-203.

Iwasaki, S. (1993). Spatial attention and two modes of visual consciousness. Cognition, 49, 211-233.

Ivanoff, J., \& Klein, R. M. (2003). Orienting of attention without awareness is affected by measurement-induced attentional control settings. Journal of Vision, 3(1), 32-40. https://doi.org/10.1167/3.1.4

Kastner, S., Deweerd, P., Desimone, R., \& Ungerleider, L. C. (1998). Mechanisms of directed attention in the human extrastriate cortex as revealed by functional MRI. Science, 282, 108-111.

Kastner, S., \& Ungerleider, L. G. (2000). Mechanisms of visual attention in the human cortex. Annual Review of Neuroscience, 23, 315-341. https://doi.org/10.1146/annurev.neuro.23.1.315

Kentridge, R. W., Heywood, C. A., \& Weiskrantz, L. (1999a). Attention without awareness in blindsight. Proceedings of the Royal Society B: Biological Sciences, 266, 1805-1811. https://doi.org/10.1098/rspb. 1999.0850

Kentridge, R. W., Heywood, C. A., \& Weiskrantz, L. (1999b). Effects of temporal cueing on residual visual discrimination in blindsight. Neuropsychologia, 37, 479-483. https://doi.org/10.1016/s00283932(98)00084-0

Kentridge, R. W., Heywood, C. A., \& Weiskrantz, L. (2004). Spatial attention speeds discrimination without awareness in blindsight. Neuropsychologia, 42, 831-835. https://doi.org/10.1016/j. neuropsychologia.2003.11.001

Kiss, M., Grubert, A., \& Eimer, M. (2013). Top-down task sets for combined features: Behavioral and electrophysiological evidence for two stages in attentional object selection. Attention, Perception, \& Psychophysics, 75, 216-228.

Kiss, M., Van Velzen, J., \& Eimer, M. (2008). The N2pc component and its links to attention shifts and spatially selective visual processing. Psychophysiology, 45, 2400-249. https://doi.org/10.1111/j.14698986.2007.00611.x

Koch, C. (2004). The quest for consciousness: A neurobiological approach. Englewood, CO: Roberts and Co.

Koch, C., \& Tsuchiya, N. (2007). Attention and consciousness: Two distinct brain processes. Trends in Cognitive Sciences, 11, 16-22.

Koch, C., \& Tsuchiya, N. (2012). Attention and consciousness: Related yet different. Trends in Cognitive Sciences, 16, 103-105.

Lamme, V. A. (2003). Why visual attention and awareness are different. Trends in Cognitive Sciences, 7, 12-18.

Lamme, V. A. F. (2006). Towards a true neural stance on consciousness. Trends in Cognitive Sciences, 10, 494-501.

Lamy, D., \& Egeth, H. E. (2003). Attentional capture in singletondetection and feature-search modes. Journal of Experimental 
Psychology: Human Perception and Performance, 29, 1003-1020. https://doi.org/10.1037/0096-1523.29.5.1003

Lamy, D., Alon, L., Carmel, T., \& Shalev, N. (2015). The role of conscious perception in attentional capture and object-file updating. Psychological Science, 26(1), 48-57. https://doi.org/10.1177/ 0956797614556777

Lamy, D., Leber, A., \& Egeth, H. E. (2004). Effects of task relevance and stimulus-driven salience in feature-search mode. Journal of Experimental Psychology: Human Perception and Performance, 30, 1019-1031. https://doi.org/10.1037/0096-1523.30.6.1019

Lien, M. C., Ruthruff, E., Goodin, Z., \& Remington, R. W. (2008). Contingent attentional capture by top-down control settings: Converging evidence from event-related potentials. Journal of Experimental Psychology: Human Perception and Performance, 34, 509-530. https://doi.org/10.1037/0096-1523.34.3.509

Lleras, A., Kawahara, J. I., Wan, X. I., \& Ariga, A. (2008). Intertrial inhibition of focused attention in pop-out search. Perception \& Psychophysics, 70, 114-131.

Luck, S. J. (2005). An introduction to the event-related potential technique. Cambridge, MA: MIT Press.

Luck, S. J., Chelazzi, L., Hillyard, S. A., \& Desimone, R. (1997). Neural mechanisms of spatial attention in areas V1, V2, and V4 of macaque visual cortex. Journal of Neurophysiology, 77, 24-42.

Luck, S. J., \& Hillyard, S. A. (1994). Electrophysiological correlates of feature analysis during visual search. Psychophysiology, 31(3), 291308. https://doi.org/10.1111/j.1469-8986.1994.tb02218.x

Luck, S. J., Woodman, G. F., \& Vogel, E. K. (2000). Event-related potential studies of attention. Trends in Cognitive Science, 4, 432-440.

Mack, A., \& Rock, I. (1998) Inattentional blindness. Cambridge, MA: MIT Press.

Maier, A., Wilke, M., Aura, C., Zhu, C., Ye, F., \& Leopold, D. (2008). Divergence of fMRI and neural signals in V1 during perceptual suppression in the awake monkey. Nature Neuroscience, 11, 11931200.

Maunsell, J. H. R., \& Cook, E. P. (2002). The role of attention in visual processing. Philosophical Transactions of the Royal Society of London B, 357, 1063-1072.

Merikle, P. M., \& Joordens, S. (1997). Parallels between perception without attention and perception without awareness. Consciousness and Cognition, 6, 219-236.

Mole, C. (2008). Attention in the absence of consciousness? Trends in Cognitive Sciences, 12, 44

Moran, J., \& Desimone, R. (1985). Selective attention gates visual processing in the extrastriate cortex. Science, 229, 782-784.

Naccache, L., Blandin, E., \& Dehaene, S. (2002). Unconscious masked priming depends on temporal attention. Psychological Science, 13, 416-424

Naughtin, C. K., Mattingley, J. B., \& Dux, P. E. (2016). Early information processing contributions to object individuation revealed by perception of illusory figures. Journal of Neurophysiology, 116, 25132522. https://doi.org/10.1152/jn.00082.2016

Oostenveld, R., \& Praamstra, P. (2001). The five percent electrode system for high-resolution EEG and ERP measurements. Clinical Neurophysiology, 112(4), 713-719.

O'Regan J. K., \& Noe, A. (2001). A sensorimotor account of vision and visual consciousness. Behavioral and Brain Sciences, 24, 939-973.

Posner, M. I. (1994). Attention: The mechanisms of consciousness. Proceedings of the National Academy of Sciences of the United States of America, 91, 7398-7403.

Prinz, J. (2011). Is attention necessary and sufficient for consciousness? In C. Mole, D. Smithies, \& W. Wu (Eds.), Attention: Philosophical and psychological essays (pp. 174-204). New York, NY: Oxford University Press.

Raz, A., \& Buhle, J. (2006). Typologies of attentional networks. Nature Reviews Neuroscience, 7, 367-379.
Reynolds, J. H., \& Chelazzi, L. (2004). Attentional modulation of visual processing. Annual Review of Neuroscience, 27, 611-647.

Reynolds, J. H., Chelazzi, L., \& Desimone, R. (1999). Competitive mechanisms subserve attention in macaque areas V2 and V4. The Journal of Neuroscience, 19(5), 1736-1753.

Sawaki, R., Geng, J. J., \& Luck, S. J. (2012). A common neural mechanism for preventing and terminating the allocation of attention. The Journal of Neuroscience, 32(31), 10725-10736.

Sawaki, R. and Luck, S. J. (2010). Capture versus suppression of attention by salient singletons: Electrophysiological evidence for an automatic attend-to-me signal. Attention, Perception, \& Psychophysics, 72(6), 1455-1470.

Schmidt, R. A. (1988). Motor control and learning: A behavioral emphasis (2nd ed.). Champaign, IL: Human Kinetics.

Schoeberl, T., Ditye, T., \& Ansorge, U. (2018). Same-location costs in peripheral cueing: The role of cue awareness and feature changes. Journal of Experimental Psychology: Human Perception and Performance, 44(3), 433-451.

Schönhammer, J. G., \& Kerzel, D. (2013). Some effects of non-predictive cues on accuracy are mediated by feature-based attention. Journal of Vision, 13, 76. https://doi.org/10.1167/13.9.76

Shedden, J. M., \& Nordgaard, C. L. (2001). ERP time course of perceptual and post-perceptual mechanisms of spatial selection. Cognitive Brain Research, 11, 59-75.

Siegel, M., Donner, T. H., Oostenveld, R., Fries, P., \& Engel, A. K. (2008). Neuronal synchronization along the dorsal visual pathway reflects the focus of spatial attention. Neuron, 60, 709-719.

Sternberg, S. (1969). The discovery of processing stages: Extensions of Donders' method. Acta Psychologica, 30, 276-315.

Tallon-Baudry, C., Bertrand, O., Henaff, M. A., Isnard, J., \& Fischer, C. (2005). Attention modulates gamma-band oscillations differently in the human lateral occipital cortex and fusiform gyrus. Cerebral Cortex, 15, 654-662.

Tallon-Baudry, C., Campana, F., Park, H. D. and Babo-Rebelo, M. (2018). The neural monitoring of visceral inputs, rather than attention, accounts for first-person perspective in conscious vision. Cortex, 102, 139-149.

Thut, G., Nietzel, A., Brandt, S. A., \& Pascual-Leone, A. (2006). Alphaband electroencephalographic activity over occipital cortex indexes visuospatial attention bias and predicts visual target detection. The Journal of Neuroscience, 26, 9494-9502.

Treue, S. (2003). Visual attention: The where, what, how and why of saliency. Current Opinion in Neurobiology, 13, 428-432.

Treue, S., \& Martínez-Trujillo, J. C. (1999). Feature-based attention influences motion processing gain in macaque visual cortex. Nature, 399, 575-579. https://doi.org/10.1038/21176

Tsuchiya, N., \& Koch, C. (2005). Continuous flash suppression reduces negative afterimages. Nature Neuroscience, 8, 1096-1101.

Tsuchiya, N., Koch, C., Gilroy, L. A., \& Blake, R. (2006). Depth of interocular suppression associated with continuous flash suppression, flash suppression, and binocular rivalry. Journal of Vision, 6 , 1068-1078.

van Boxtel, J. J. A. (2017). Different signal enhancement pathways of attention and consciousness underlie perception in humans. The Journal of Neuroscience, 37, 5912-5922.

van Boxtel, J. J., Tsuchiya, N., \& Koch, C. (2010). Consciousness and attention: On sufficiency and necessity. Frontiers in Psychology, 1, 217. https://doi.org/10.3389/fpsyg.2010.00217

Vanduffel, W., Tootell, R. B. H., \& Orban, G. A. (2000). Attentiondependent suppression of metabolic activity in the early stages of the macaque visual system. Cerebral Cortex, 10, 109-126.

Velmans, M. (1996). The science of consciousness. New York, NY: Routledge.

Wascher, E., \& Wauschkuhn, B. (1996). The interaction of stimulusand response-related processes measured by event-related lateralizations of the EEG. Electroencephalography and Clinical 
Neurophysiology, 99, 149-162. https://doi.org/10.1016/00134694(96)95602-3

Watanabe, M., Cheng, K., Murayama, Y., Ueno, K., Asamizuya, T., Tanaka, K., \& Logothetis, N. (2011). Attention but not awareness modulates the BOLD signal in the human V1 during binocular suppression. Science, 334, 829-831.

Wauschkuhn, B., Verleger, R., Wascher, E., Klostermann, W., Burk, M., Heide, W., \& Kompf, D. (1998). Lateralised human cortical activity for shifting visuospatial attention and initiating saccades. Journal of Neurophysiology, 80, 2900-2910.

Wolfe, J. M. (1994). Guided Search 2.0: A revised model of visual search. Psychonomic Bulletin and Review, 1, 202-238.

Woodman, G. F., \& Luck, S. J. (1999). Electrophysiological measurement of rapid shifts of attention during visual search. Nature, 400, 867-869. https://doi.org/10.1038/23698

Woodman, G. F., \& Luck, S. J. (2003a). Dissociations among attention, perception, and awareness during object-substitution masking.
Psychological Science, 14(6), 605-611. https://doi.org/10.1046/j. 0956-7976.2003.psci 1472.x

Woodman, G. F., \& Luck, S. J. (2003b). Serial deployment of attention during visual search. Journal of Experimental Psychology: Human Perception and Performance, 29(1), 121-138. https://doi.org/10. 1037/0096-1523.29.1.121

Worden, M. S., Foxe, J. J., Wang, N., \& Simpson, G. V. (2000). Anticipatory biasing of visuospatial attention indexed by retinotopically specific alpha-band electroencephalography increases over occipital cortex. The Journal of Neuroscience, 20, RC63.

Wyart, V., \& Tallon-Baudry, C. (2008). A neural dissociation between visual awareness and spatial attention. The Journal of Neuroscience, $28,2667-2679$.

Yantis, S. and Egeth, H. E. (1999). On the distinction between visual salience and stimulus-driven attentional capture. Journal of Experimental Psychology: Human Perception and Performance, 25, 661-676. https://doi.org/10.1037/0096-1523.25.3.661 